\title{
Advances in Tissue Culture of Cucurbits: A Review
}

\author{
Sangram S. Dhumal ${ }^{1 *}$, B. Veerendra Naik ${ }^{1}$ and Mansinghraj S. Nimbalkar ${ }^{2}$ \\ ${ }^{1}$ Department of Horticulture, Rajarshee Chhatrapati College of Agriculture, Kolhapur-416 \\ 004, Maharashtra, India (Mahatma Phule Krishi Vidyapeeth, Rahuri, Maharashtra, India) \\ ${ }^{2}$ Department of Botany, Shivaji University, Kolhapur-416 004, Maharashtra, India
}

*Corresponding author

\section{A B S T R A C T}

\begin{tabular}{|l|}
\hline Ke y w o r d s \\
$\begin{array}{l}\text { Tissue culture, } \\
\text { Cucurbits }\end{array}$ \\
\hline Article Info \\
\hline $\begin{array}{l}\text { Accepted: } \\
\text { 22 July 2020 } \\
\text { Available Online: } \\
\text { 10 August } 2020\end{array}$ \\
\hline
\end{tabular}

\section{Introduction}

Crops belongs to Cucurbitaceae are generally known as cucurbits or gourds. The family Cucurbitaceae is largest among the known vegetables comprising of 117 genera and includes 825 species in tropical parts of the world. It includes the cucumber, Squashes, Pumpkin, Luffa, Melons, Watermelon, Spine gourd, Sweet gourd, Bottle gourd, Sponge gourd, Snake gourd, Pointed gourd etc. It is widely distributed around the tropics. It is also listed in the earliest cultivated plantsof old and new world for the edible fruits and vegetables. It consists of wide range of vegetables which can be used in various purposes such as, salad (cucumber), for cooking (all type of gourds), pickling (gherkins), as a dessert food (Musk melon and watermelon) and as a candy (ash gourd). The Cucurbitaceae family consists of widely spread and genetically diverse group of plants. It occupies largest area through out the world. This genetically diversified group of plant includes traditional cultivars, landraces, edible as well as nonedible wild and cultivated forms, weedy species and related non-edible wild species.

Its use is important because of some vital minerals, calories, or vitamins. The most of the cucurbits generally contain low to moderate nutrients, however few exceptions like Pumpkin (Vit-A, 1600 IU/100g), Bitter 
gourd (rich in Vit-C, 96mg/100g), Kakrol (High protein, $3.1 \mathrm{~g} / 100 \mathrm{~g}$ ) are also reported. Moreover, the cucurbit seeds more valued for their protein and high oil contents. Seed proteins which are rich in methionine, are comparable with the legumes. Cucurbit crops are very important for small land holding farmers and this is cash crop for several rural families. In Tropical countries, a number of minor and major cucurbits are cultivated as a popular kitchen gardening crop and considering its crop duration it is also included in cropping system a cash crop.

The large-scale production of sex specific plants in cucurbits using the conventional propagation methods has several limitations. These limitations have forced many scientists to look forward towards tissue culture because of its immense potential in efficient clonal propagation. Improvement of plant species via biotechnological approach depends largely on plant tissue culture. Micropropagation helps to overcome the problems in conventional method of propagation in great extent and systematic improvement is boon for Horticulture, pharmaceutical industry and Ayurveda, high multiplication ratio achieved rapid multiplication of disease and pest free elite plant within short span of time and space (Ghive. 2006). The major advantage of getting unlimited planting material can be achieved using in-vitro propagation, irrespective of season of growing. The better genetic upgradation is possible using nonconventional approaches such as plant tissue culture. Its application mainly depends on a reliable and successful plant regeneration system. Many scientists have successfully developed micropropagation protocol for the commercial production of many crops including cucurbitaceous vegetables. The purpose of this review article is to present the recent advancements, current status and developments in micropropagation techniques in cucurbitaceous crops. It also focuses on the increasing collective interest in the search of new protocols and major findings of nonconventional techniques of propagation in cucurbitaceous vegetable crops.

\section{Traditional methods of propagation in cucurbits}

\section{Seed}

At present most of the cucurbits are propagated by seeds like water melon, cucumber, Luffa, squashes etc. but using of seed for propagation in most of the crop is shows the late germination and uneven germination, some may remain in soil as it is due to dormancy.

\section{Cuttings}

Using of the cutting is the only way of propagation in some species of cucurbits like pointed gourd and ivy gourd, while using cuttings major problem is the less sprouting and rooting.

\section{Tubers}

Underground storage organs like tubers also used for propagation in Spine gourd and other crops but main threat in using of tubers is low rate of multiplication and improper establishment in the field.

\section{Strategies for tissue culture}

\section{Micropropagation}

Micropropagation have been attempted by using apical bud, axillary bud and cotyledon in various crops like Momordica dioica (Kulkarni. 1999, Choudhary et al., 2017, Ghive et al., 2006 ${ }^{\mathrm{b}}$, Jamatia. 2016, Karim and Ullah. 2011, Arekar. 2012, Mustafa et al., 2012, Jadhav. 2015, Shekhawat et al., 2011, 
Govind et al., 2012, Thiruvengadam et al., 2012 and Kapadia. 2018),Momordica sahyadrica (Rajashekharan et al., 2012), Cucumis melo (Venkateshwaralu. 2012, Parvin et al., 2013, Huda and Sikdar. 2006, Faria et al., 2013, Keng and Hoong. 2005, Venkateshwaralu et al., 2010, Randall et al., 1989.), Trichosanthesdioica (Abdul-awal et al., 2005, Komal. 2011 ${ }^{\mathrm{c}}$, Malex et al., 2010), Cucumis sativus (Mohammadi and Siveritepe. 2007, Ahamad and Anis. 2005, Kielkowska and Havey. 2011), Cucumis sativus by using MS + Kinetine $(6 \mu \mathrm{m})$ (Sangeetha et al., 2011, Firoz Alam et al., 2015), Cucurbita maxima (Mahzabin. 2008), Watermelon (Khalekuzzaman et al., 2012, Li et al., 2011, Khatun et al., 2010 , Suratman, 2009, Chaturvedi and Bhantnagar. 2001), Trichosanthescucumerina (Devendra et al., 2008, Kawale et al., 2009.), Benincasahispida (Kausar et al., 2013, Haque et al., 2008), Cucumis hystrix (Compton et al., 2001), Momordica charantia (Verma et al., 2014, Sultan. 2005, Sultana. 2003.), Cucumis anguria (Margareate, 2014), Momordica balsamina (Thakur et al., 2011), Sechiumedule (Abdelnour et al., 2002), Citrullus colocynthis. (Rama Krishna and Shashtri. 2014), Luffa acutangula (Zohura et al., 2013)), Cucurbita ficifolia (Kim et al., 2009).

\section{Somatic embryogenesis}

The many pioneer scientists are worked on cucurbits with an objective to explore the potentiality of somatic embryogenesis, viz., Cucurbita pepo (Paula. 1992), Momordica dioica (Hoque et al., 2007 and Karim and Ahamad, 2010) with a highest percentage of callus in internodal explants, Cucumis sativus (Hisajima and Arai. 1989,Elmeer et al., 2009 and Usman et al., 2011), Cucumis melo (Gray et al., 1993), Cucurbita moschata (ValdezMelara et al., 2009), Momordica charantia (Thiruvengadam et al., 2006), Cucurbita pepocv. YC60 (Paula et al., 1990) and Momordica dioica (Raju et al., 2015).

\section{Organogenesis}

Many scientists have also worked on direct and indirect organogenesis in order to produce callus in cucurbits. The organogenesis in Momordica dioica was studied by Nabi et al., $\left(2002^{\mathrm{a}}\right)$, Swamy et al., (2015), Devendra (2009), Nabi et al., (2002 b), Karim (2013), Hoque et al., (2000), Karim (2011), Patel (2015), Debnath (2013), Mustafa et al., (2012) and Thiruvengadam et al., (2007). Thiruvengadam et al., (2012) used MS and Gamboge + NAA $(3.0 \mu \mathrm{m})+$ TDZ $(1.0 \mu \mathrm{m})+$ Putrecine $(1.0 \mu \mathrm{m})$ to induce the callus in Momordica dioca. Similarly organogenesis was studied in Luffa cylindrical by Srivastava and Roy. 2012, Han et al., 2004 and in Citrullus lunatus by Sultana (2004) Vedat Pirinc et al., 2002, Khatun et al., 2010 and Compton and Grey (1992)who developed the triploid water melon. The scientists Krug et al., 2005 used the coconut water along with media to induce the good callus in watermelon. The organogenesis was also reported in Momordica charantia (Saima malik. 2007), Citrullus colocynthis (Shasthree et al2014), Trichosanthesdioica (Sourab et al., 2017), Cocciniaabyssinica (Guma et al., 2015), Cucumis melo (Rahaman et al., 2012), Cucumis trigonus (Satapathy et al., 2014), Citrullus colocynth (Savitha et al., 2010), Luffa acutangula (Umamaheshwari et al., 2014, Vellivella. 2016, Moideen and Prabha. 2014). Moideen and Prabha (2013) concluded that best callusogenesis response in Luffa acutangular was observed in media treated with 2, 4-D + TDZ-2.0mg/l. The effect of commercial fruit juices on callus induction in Cucumis sativus was also studied by Ikram-ul Haq et al., (2013). The organogenesisin Cucumis sativus was also reported by Selvaraj et al., (2006), Jesmin and Mian (2016). 
Similarly it is also reported in Cucurbita pepo (Pal et al., 2007), Lagenariasiceraria (Hasbullah et al., 2007), Benincasahispida (Thomas et al., 2004), Cucumis figarei and Cucumis metuliferus (Yutaka et al., 1998), M omordica cochinchinensis (Debnath et al., 2013) and Momordica cymbalarias (Devi et al., 2017).

\section{Other}

Thiruvengadam et al., (2006), optimized a somatic embryogenesis system using embryogenic suspension culture in bitter melon. In Spine gourd, Thiruvengadam et al.(2013), evaluated an efficient method of somatic embryogenesis using exogenous polyamines through suspension culture. Ghive et al., (2006) reported the highest survival and establishment rate in spine gourd with healthy shoots on its own root systems. Thiruvengadam et al., (2013) achieved somatic embryogenesis from cell suspension cultures in Cucumis anguria. While Claveria et al., (2005) concluded that homozygous doubled haploid lines in cucumber were helpful to breed resistant varieties. Agrobacterium mediated genetic transformation had been also carried out in several crops viz., Cucumis melo (Chovelon. 2008, Bezirganoglu et al., 2014), Cucumis sativus (Nanasato et al., 2013), Citrullus colocynthis (Dadauza et al., 1997) and Sponge gourd (Singh et al., 2011).

\section{Choice of explant}

\section{Apical bud}

Apical bub is the one of standardized explant for the in-vitro propagation. Several scientists have tried apical bud as an explant in cucurbitaceous crops in their investigations viz., Benincasa hispida (Haque et al., 2008, Kausar et al., 2013), Citrullus lanatus (Compton and Grey. 1992, Khalekuzzaman et al., 2012, Vedat et al., 2002), Cucumis hystrix
[Compton et al., 2001 got the successful plantlet using combinations of growth regulators like MS + Sucrose $(30 \mathrm{~g})+$ myoinositol (0.1g) + Agargelplus (5g) + IBA $(1.7 \mu \mathrm{M})+$ Kinetin $(0.5 \mu \mathrm{M})+\mathrm{GA} 3(0.3 \mu \mathrm{M})]$, Cucumis melo (Faria et al., 2013, Huda and Sikdar 2006, Venkateshwaralu. 2012), Cucumis sativus (Mohammadi and Siveritepe. 2007, Sangeetha et al., 2011), Cucurbita maxima (Mahazabin. 2008), Cucurbita pepo (When most of the scientists used the apical bud for the micropropagation, Paula et al., (1990) reported somatic embryogenesis by apical bud), interspecific Cucurbita hybrid (Sarowar et al., 2003), Trichosanthesdioica (Abdul-Awal et al., 2005) and Trichosanthes cucumerina (Devendra et al., 2008).

\section{Axillary bud}

The use of axillary bud was reported in Citrullus lanatus (Khatun et al., 2010 ), Cucumis anguria (Margareate, 2014), Cucumis melo (Parvin et al., 2013), Cucumis sativus (Ahamadand Anis. 2005, Firoz Alam et al., 2015), Cucurbita maxima (Hoque et al., 2008), Momordica balsamina (Thakur et al., 2011), Momordica charantia (Sultana et al., 2003, Sultana et al., 2005, Verma et al., 2014), Momordica cymbalarica (Devi et al., 2017), Momordica dioica (Choudhary et al., 2017, Debnath, 2013, Ghive et al., 2006 ${ }^{\mathrm{b}}$, Govind et al., 2012, Jadhav, 2015, Kapadia, 2018, Kulkarni, 1999, Mustapha et al., 2012, Mustapha et al., 2013, Patel and Kalpesh, 2015, Shekhawat et al., 2011.), Trichosanthes dioica (Komal. 2011 ${ }^{\mathrm{a}}$, Komal 2011 ${ }^{\mathrm{b}}$, Komal $2011^{\mathrm{c}}$ ). Venkateshawaralu et al., 2010 used BAP 1 and $2 \mathrm{mg}$ however Keng and Hoong 2005 used BAP $8.0 \mathrm{mg}$ and found good result of plant initiation by using axillary bud in Cucumis melo. A good percentage of callus was obtained from the axillary buds in Momordica cochinchinensis in MS agar gelled + 2, 4-D (2mg) + Coconut milk (15\% v/v) (Debnath et al., 2013). 


\section{Leaf}

Citrullus colocynth (Devendra, 2009; Guma et al., 2015), Citrullus lanatus (Moideen and Prabha, 2013), Cocciniaabyssinica(Raju et al., 2015 reported molecular confirmation of sex by leaf explant), Cucumis anguria (Saima malik et al., 2007), Cucumis melo (Satapathy et al., 2014), Cucumis sativus (Savitha et al., 2010), Cucumis trigonus (Shashtree et al., 2014), Luffa acutangula (Sourab et al., 2017), Luffa cylindrical (Srivastava and Roy. 2012), Momordica charantia (Sultana et al., 2004, Swamy et al., 2015), Momordica dioica [(Thiruvengadam et al., 2006,Usman et al., 2011)], Trichosanthesdioica (Rahaman et al., 2012). In Momordica dioica, Thiruvengadam et al., 2013, found somatic embryogenesis in MS media supplemented with 2, 4-D $(3.3 \mu \mathrm{m})$ + Putrecine $(0.5 \mu \mathrm{m})$ using leaf as an explant.

\section{Cotyledon}

Beninca sahispida (Thomas et al., 2004), Citrullus colocynth(Rama Krishna and Shashtri. 2015, found the best results for rhizogenesis by cotyledon explant), Citrullus lanatus [(Suratman et al., 2009, Dadauza et al., 1997, Khatun et al., 2010a, Krug et al., 2005, Li et al., 2011)], Cucumis figarei (Yutaka et al., 1998), Cucumis melo (Chovelon et al., 2008, Grey et al., 1993, Bezirganoglu et al., 2014, Randall et al., 1989), Cucumis metuliferus (Yutaka et al., 1998), Cucumis sativus (Yutaka et al., 1998, Nanasato et al., 2013, Hisajima and Arai. 1989), Cucurbita ficifolia (Kim et al., 2010), Cucurbita moschata (Valdez-Melara et al., 2009), Cucurbita pepo (Paula. 1992), Lagenaria siceraria (Han et al., 2004), Luffa acutangula (Umamaheshwari et al., 2014), Zohura et al., (2013), Luffa cylindrical (Singh et al., 2011), Trichosanthescucumerina (Kawale and Choudhary, 2009), Trichosanthes dioica (Malex et al., 2010) and in Momordica dioica (Hoque et al., 2000,
Karim, 2013, Karim and Ullah. 2011, Nabi et al., 2002 $2^{\mathrm{a}}$, Nabi et al., 2002 ${ }^{\mathrm{b}}$ and Karim. 2011). All the scientists used cotyledon as an explant in Spine gourd on a MS media supplemented with BAP $1.0 \mu \mathrm{m}$ +NAA0.1 $\mu$ mhoweverArekar (2012), used BAP $(4.44$ and $8.88 \mu \mathrm{m})$. Chaturvedi and Bhantnagar, 2001, used MS + BAP $(3.0 \mu \mathrm{M})+$ $2 \mathrm{iP}(3.0 \mu \mathrm{M})$ and showed best result in Citrullus colocynth using cotyledon explant.

\section{Other explants}

The other explants used by many scientists include leaf node, somatic embryo, hypocotyle etc. and got success to some extent. A recent work on cucurbits using explants other than leaf, cotyledons, apical and axillary buds is reported hereunder crop wise. Leaf node was used as an explant in Cucumis meloby Rahaman et al., 2012. In Cucumis sativus, cuttings (Ikram-ul haq et al., 2013), hypocotyle (Selvaraj et al., 2006), parthenogenic embryo (Claveria et al., 2005), somatic embryo (Elmeer et al., 2009) and stem (Jesmine and Mian 2016 and Kiełkowska and Havey, 2011) were used as an explant. The use of hypocotyl as an explant was also recorded in Cucurbita pepo (Pal et al., 2007). The stem fragments were used in Lagenariasiceraria by Hasbullah. 2017 while in Luffa acutangula, Moideen and Prabha (2014) and Vellivella et al., (2016) used petiole as an explant. Similarly, the petiole was also used to get success in Momordica charantia by Thiruvengadam et al., (2012). The encapsulated shoot tips (Thiruvengadam et al., 2012), healthy shoots (Ghive et al., $2006^{\mathrm{a}}$ ), immature embryo (Hoque et al., 2007), internode (Karim and Ahamad. 2010), node and leaf (Jamatia. 2016) and leaf (Thiruvengadam et al., 2007) were used as an explant in Momordica dioica. Rajashekharan et al., (2012) used seedling explants in Momordica sahyadrica while stem in Sechiumedule (Abdelnour et al., 2002) and 
cotyledonary nodes in Trichosanthes cucumerina (Kawale and Choudhary, 2009).

\section{Effect of growth regulators}

\section{Micropropagation}

\section{Apical bud}

In Spine gourd, Thiruvengadam et al., (2012) developed efficient protocol for in vitro regeneration by using encapsulated shoot tip as an explant. They obtained 100 per cent conversion into plantlets from encapsulated shoot tip explants when placed on $0.5 \mu \mathrm{M}$ BAP supplemented full strength MS containing the $0.7 \%$ agar. Hardened and acclimatized plant in field reported the $90 \%$ survival rate and grew well without considerable variation. Kausar et al., (2013) in Benincasahispida used shoot tip and node as explant but shoot tip showed the highest rate of multiple shoots at $1.5 \mathrm{mg} / 1 \mathrm{BAP}+$ $0.2 \mathrm{mg} / \mathrm{l} \mathrm{GA}_{3}$, wherenormal number of shoots per culture recorded was 5.55. The lower concentration of $\mathrm{GA}_{3}$ inducd multiple shoots effectively. When Kausar et al(2013)used only BAP and $\mathrm{GA}_{3}$, Huda and Sikdar (2006)used not only BAP and GA3 but also in combination With IBA and found good shoot initiation and elongation. Shoot proliferation rate, shoot quality, and other parameters showed best result at the combination of MS with BAP $0.4 \mu \mathrm{M}$. The highest rooting frequencies were observed in PGR free medium (Mohammadi and Siveritepe, 2007). In Trichosanthes cucumerina, after $4^{\text {th }} \mathrm{sub}$ culture maximum number of shoots $12.00 \pm 0.70$ were recorded at concentration of BAP $1.0 \mathrm{mg} / \mathrm{l}$ in combination with lower amount of NAA $0.1 \mathrm{mg} / \mathrm{l}$. Out of different chemical combinations used $100 \%$ multiple shoot formation was noticed in BAP $1 \mathrm{mg} / \mathrm{l}+$ NAA 0.2mg/l (Devendra et al., 2008, AbdulAwal et al., 2005). Wherever Shoot tip is used as explant BAP is used up to $3.0 \mathrm{mg} / 1$ concentration but in Citrullus lanatus combination of MS + BAP (5.0) + IAA (0.1) registered maximum frequency $(73 \%)$ with better growth response. The percentage of successful hardening (72\%) from regenerated plantlets was recorded with best survival in the soil condition (Khalekuzzaman et al., 2012). For the induction of the multiple shoots in shoot tip explants MS augmented with IAA $\left(0.5 \mathrm{mgl}^{-1}\right)+$ BAP $\left(2.0 \mathrm{mgl}^{-1}\right)$ was proved to be best (Venkateshwaralu. 2012). Efficient cloning of Cucumis hystrix was also reported using $1 \mathrm{~mm}$ shoot-tip explants. Establishment of Stage I cultures was greatest $(83 \%)$ when shoot tips were cultured on (per liter) $30 \mathrm{~g}$ sucrose, $0.1 \mathrm{~g}$ myo-inositol, and $5 \mathrm{~g}$ Agargelplus, $1.7 \mu \mathrm{M}$ IBA, $0.5 \mu \mathrm{M}$ kinetin and $0.3 \mu \mathrm{M} \mathrm{GA} 3$ (IKG). Among all the growth regulators tried, BAP $5 \mu \mathrm{M}$ proved best for Stage II shoot proliferation. It was also observed that plantlet height influenced acclimatization and over $72 \%$ of plantlets survived (Compton et al., 2001).

Rajashekharan et al., (2012) conducted investigation on conservation and in-vitro propagation of Momordica sahyadrica species. In-vitro grown seedlings were selected as explants and cultured on modified MS fortified with the BAP. Shoot and root differentiation was reported on the MS media supplemented with BAP+IBA/NAA. MS media without hormones reported the induction of multiple shoots with good number of roots. Finally $40 \%$ of the plants were survived after transplanting to the exvitro field condition. Most of the research scientist reported that the BAP in the concentration range of $1.0-3.0 \mathrm{mg}$ gave good results with the shoot tip as an explant in Cucumis sativus, Cucumis melo, Cucurbita maxima (Sangeetha et al., 2011,Faria et al., 2013, Mahazabin. 2008) but some scientist were reported that usage of BAP in combination with NAA and IAA in the range of $0.1-0.5 \mathrm{mg}$ helps in establishment of the 
plant (Abdul-Awal et al., 2005, Devendra et al., 2008, Khalekuzzaman et al., 2012, Venkateshwaralu, 2012).

\section{Axillary bud}

In plant tissue culture technique, most of the axillary buds were used to get multiple shoots due to absence of apical dominance. Most of the pioneer investigators used the BAP in the range of $0.5,1.0,1.5$, and 2.0 alone or in combination with the different growth regulators for nodal explants (Verma et al., 2014, Ahamad and Anis. 2005,Jamatia. 2016, Choudhary et al., 2017, Margareate. 2014, Thakur et al., 2011, Venkateshawaralu et al., 2010, Jadhav.2015, Khatun et al., 2010 , Kapadia. 2018, Firoz Alam et al., 2015, Sultana et al., 2005, Hoque et al., 2008, Parvin et al., 2013, Shekhawat et al., 2011, Sultana et al., 2003) but Keng and Hoong (2005)reported that multiple shoots could be induced on MS supplemented with $8.0 \mathrm{mg} / 1$ BAP in Musk melon cv. Honey dew (Cucumis melo). When majority of the scientists reported to use the full strength MS medium for their research purpose, Verma et al., (2014)used half strength MS with 0.5 $\mathrm{mg} / \mathrm{l}$ BAP in monoecious bitter melon and reported more number of shoots (3.4) after $3^{\text {rd }}$ sub culture with shoot length $(2.7 \mathrm{~cm})$. Addition of casein hydrolysate $200 \mathrm{mg} / \mathrm{l}$ to the shoot induction medium (MS + BAP) significantly enhanced the number of multiple shoots in Cucumis sativus $L$. but casein hydrolysate $200 \mathrm{mg} / 1+0.9 \mu \mathrm{M}$ BAP helped in enhancing the axillary shoot proliferation in case of nodal explants of Spine gourd. Highest number of shoots i.e., 6.2 shoots per explants was recorded with the $100 \%$ shoot regeneration frequency. Especially in case of male genotype $\mathrm{CH}$ helped in inducing the callus formation healthy shoots and proved inhibitory action for the shoot length and shoot differentiation (Ahamad and Anis. 2005, Govind et al., 2012). Good amount of compact, green callus and organogenesis is obtained in $2.0 \mathrm{mg} / 1$ 2, 4-D + 1.0mg/l BAP in Momordica dioica (Mustafa et al., 2012). In Momordica dioica itself MS + $\mathrm{AdSO}_{4}(70 / 80)$ + BAP (1.0) + NAA (1.0) is used to get a maximum number of multiple shoots whereas the highest number of shoots $45.30 \pm 3.83$ with average length of shoot $6.52 \pm 0.89 \mathrm{~cm}$ were differentiated on MS + BAP (0.5) + IAA (0.1) + Ascorbic acid (50)+ Adenine sulphate, Citric Acid, L-arginine (25), later regenerated plants were evaluated for genetic stability. For this, PCR techniques like RAPD and ISSR were used for the amplification of the micropropagated plants and mother plants which found to be monomorphic in nature depicting the genetic stability of the in-vitro propagated plants (Ghive et al., 2006 ${ }^{\text {b, }}$ Choudhary et al., 2017). In Cucumis melo var utillisimushighest concentration of Adenine sulphate $(15 \mathrm{mg} / \mathrm{l})$ in combination with BAP were found to be best for multiple shoot induction (Venkateshawaralu et al., 2010). In case of Momordica dioica, Citrullus lunatus and Momordica charantia BAP 1.0 or 2.0 $\mathrm{mgl}^{-1}$ in combination with NAA 0.1 or 0.2 $\mathrm{mgl}^{-1}$ were used for early shoot initiation, establishment and maximum shoot multiplication with significantly more height and good percentage of acclimatize and successful survival of rooted plants in ex-vitro condition (Jadhav. 2015, Khatun et al., 2010 ${ }^{\mathrm{b}}$, Kapadia. 2018, Sultana et al., 2003).

Sultan (2005) used nodal explants of Momordica charantia in a media with different levels of $\mathrm{pH}$ and agar infused with different concentrations of sucrose. Maximum shoot induction was recorded in medium containing $\mathrm{MS}+2.0 \mathrm{mg} / \mathrm{l} \mathrm{BAP}+0.2 \mathrm{mg} / \mathrm{l} \mathrm{NAA}$, with $30 \mathrm{~g} / \mathrm{l}$ sucrose, $7 \mathrm{~g} / \mathrm{l}$ agar and 5.5-6.0 level $\mathrm{pH}$ (Table 1). 
Table.1

\begin{tabular}{|c|c|c|c|c|c|}
\hline \multicolumn{6}{|c|}{ Review of Literatures in table form } \\
\hline $\begin{array}{l}\text { Sr. } \\
\text { No. }\end{array}$ & Crop & Explant & Best treatments $\left(\mathrm{mgl}^{-1}\right)$ & Result & Author \\
\hline 1 & Sechiumedule & Stem part & $\mathrm{MS}+\mathrm{BAP}(0.1)$ & Full plantlet in soil & $\begin{array}{l}\text { Abdelnour et al., } \\
(2002)\end{array}$ \\
\hline 2 & Trichosanthesdioica & Shoot tip & $\begin{array}{l}\mathrm{MS}+\mathrm{BAP}(1.0)+\mathrm{NAA} \\
(0.2)\end{array}$ & Full plantlet in soil & $\begin{array}{l}\text { Abdul-Awal, et } \\
\text { al., (2005) }\end{array}$ \\
\hline 3 & Cucumis sativus $L$. & Node & $\begin{array}{l}\mathrm{MS}+\mathrm{BAP}(1.0 \mu \mathrm{M})+ \\
\text { Casein hydrolysate }(200)\end{array}$ & Full plantlet in soil & $\begin{array}{l}\text { Ahamad and Anis } \\
\text { (2005) }\end{array}$ \\
\hline 4 & Momordica dioica & Cotyledon & $\begin{array}{l}\mathrm{MS}+\mathrm{BAP}(4.44 \text { and } \\
8.88 \mu \mathrm{m})\end{array}$ & Full plantlet in soil & Arekar (2012) \\
\hline 5 & Cucumis melo $L$. & Cotyledon & $\begin{array}{l}\text { Bacteria concentration of } \\
\mathrm{OD}_{600} 0.6 \text {, inoculation } \\
\text { for } 30 \mathrm{~min},\end{array}$ & $\begin{array}{l}\text { Genetic } \\
\text { transformation }\end{array}$ & $\begin{array}{l}\text { Bezirganogalu, } \\
\text { et al., (2014) }\end{array}$ \\
\hline 6 & Citrullus lanatus & Cotyledon & $\begin{array}{l}\text { MS + BAP }(3.0 \mu \mathrm{M})+2 \mathrm{PP} \\
(3.0 \mu \mathrm{M})\end{array}$ & Full plantlet in soil & $\begin{array}{l}\text { Chaturvedi et al., } \\
\text { (2001) }\end{array}$ \\
\hline 7 & Momordica dioica & Node & $\begin{array}{l}\mathrm{MS}+\mathrm{BAP}(0.5)+\text { IAA } \\
(0.1)+\text { Ascorbic acid } \\
(50)+\text { Adenine sulphate, } \\
\text { Citric Acid, L-arginine } \\
(25)\end{array}$ & $\begin{array}{l}\text { Full plants in soil, } \\
\text { monomorphic, } \\
\text { genetic stability }\end{array}$ & $\begin{array}{l}\text { Choudhary, et al., } \\
\text { (2017) }\end{array}$ \\
\hline 8 & Cucumis melo $L$. & Cotyledon & $\mathrm{MS}+\mathrm{BAP}+2.0-\mathrm{iP}$ & $\begin{array}{l}\text { Agrobacterium } \\
\text { mediated Genetic } \\
\text { transformation }\end{array}$ & $\begin{array}{l}\text { Chovelon, et al., } \\
(2008)\end{array}$ \\
\hline 9 & Cucumis sativus $L$. & $\begin{array}{l}\text { Parthenogenic } \\
\text { embryo }\end{array}$ & $\begin{array}{l}500 \text { gamma radiation, Co } \\
60 \text { Y-rays source }\end{array}$ & $\begin{array}{l}\text { Haploid } \\
\text { production }\end{array}$ & $\begin{array}{l}\text { Claveria, et al., } \\
(2005)\end{array}$ \\
\hline 10 & Citrullus lanatus & Shoot tip & $\mathrm{MS}+\mathrm{BAP}(1.0)$ & Full plantlet in soil & $\begin{array}{l}\text { Compton and } \\
\text { Grey (1992) }\end{array}$ \\
\hline 11 & Cucumis hystrix & Shoot tip & $\begin{array}{l}\mathrm{MS}+\text { Sucrose }(30 \mathrm{~g})+ \\
\text { myo-inositol }(0.1 \mathrm{~g})+ \\
\text { Agargelplus }(5 \mathrm{~g})+\mathrm{IBA} \\
(1.7 \mu \mathrm{M})+\mathrm{Kinetin} \\
(0.5 \mu \mathrm{M})+\mathrm{GA}_{3}(0.3 \mu \mathrm{M})\end{array}$ & Full plantlet in soil & $\begin{array}{l}\text { Compton, et al., } \\
\text { (2001) }\end{array}$ \\
\hline 12 & Citrullus lanatus & Cotyledon & $\begin{array}{l}\text { Agrobacterium } \\
\text { tumefaciens LBA4404 + } \\
\text { vector pBI121 }+\mathrm{r} \text { gene } \\
\beta \text {-glucuronidase (gus) }+ \\
\text { neomycin } \\
\text { phosphotransferase }(n p t I I)\end{array}$ & For transgenic & $\begin{array}{l}\text { Dabauza, et al., } \\
\text { (1997) }\end{array}$ \\
\hline 13 & Cucurbitaceae & Cotyledon & & $\begin{array}{l}\text { Reviewed somatic } \\
\text { embryogenesis }\end{array}$ & $\begin{array}{l}\text { Debeaujon and } \\
\text { Brancherd (1993) }\end{array}$ \\
\hline 14 & Momordica dioica & Node & $\begin{array}{l}\mathrm{MS}+2,4-\mathrm{D}(2.0)+\mathrm{BAP} \\
(0.5) / \text { Coconut milk }\end{array}$ & Organogenesis & $\begin{array}{l}\text { Debnath et al., } \\
\left(2013^{\mathrm{a}}\right)\end{array}$ \\
\hline
\end{tabular}




\begin{tabular}{|c|c|c|c|c|c|}
\hline & & & $(15 \% \mathrm{v} / \mathrm{v})$ & & \\
\hline 15 & $\begin{array}{l}\text { Momordica } \\
\text { cochinchinensis }\end{array}$ & Node & $\begin{array}{l}\text { MS agar gelled }+2 \text {, } 4-\mathrm{D} \\
(2.0)+\text { Coconut milk } \\
(15 \% \mathrm{v} / \mathrm{v})\end{array}$ & Callus & $\begin{array}{l}\text { Debnath, et al., } \\
\left(2013^{\mathrm{b}}\right)\end{array}$ \\
\hline 16 & Momordica dioica & Leaf & $\begin{array}{l}\mathrm{MS}+2,4-\mathrm{D}(1.0)+ \\
\mathrm{BAP}(2.0)\end{array}$ & Organogenesis & $\begin{array}{l}\text { Devendra et al., } \\
\text { (2009) }\end{array}$ \\
\hline 17 & Trichosanthescucumerina & Shoot tip & $\begin{array}{l}\text { MS + BAP (1.0)+ NAA } \\
(0.1)\end{array}$ & Full plantlet in soil & $\begin{array}{l}\text { Devendra et al., } \\
\text { (2008) }\end{array}$ \\
\hline 18 & Momordica cymbalarica & Node & $\mathrm{MA}+\mathrm{BAP}(2.0)$ & Full plantlet in soil & Devi, et al., (2017) \\
\hline 19 & Cucumis sativus $L$. & $\begin{array}{l}\text { Somatic } \\
\text { embryo }\end{array}$ & $\begin{array}{l}\text { Primers (OP-C10, OP- } \\
\text { G14, OP-H05, OP-Y03 } \\
\text { and OP-AT01) }\end{array}$ & $\begin{array}{l}\text { Genetic stability } \\
\text { by RAPD }\end{array}$ & $\begin{array}{l}\text { Elmeer, et al., } \\
(2009)\end{array}$ \\
\hline 20 & Cucumis melo $L$. & Shoot tip & $\mathrm{MS}+\mathrm{BAP}(2.0)$ & Full plantlet in soil & $\begin{array}{l}\text { Faria, et al., } \\
(2013)\end{array}$ \\
\hline 21 & Cucumis sativus $L$. & Node & (1.5) & Full & $\begin{array}{l}\text { Firoz Alam, et al., } \\
\text { (2015) }\end{array}$ \\
\hline 22 & Momordica dioica & $\begin{array}{l}\text { Healthy } \\
\text { shoots }\end{array}$ & $\mathrm{MS}+\mathrm{IBA}(1.0)$ & $\begin{array}{l}\text { Highest percent of } \\
\text { rooting }\end{array}$ & $\begin{array}{l}\text { Ghive } \\
\left(2006^{\mathrm{a}}\right)\end{array}$ et al., \\
\hline 23 & Momordica dioica & Node & $\begin{array}{l}\mathrm{MS}+\mathrm{AdSO}_{4}(70 / 80)+ \\
\mathrm{BAP}(1.0)+\mathrm{NAA}(1.0)\end{array}$ & Multiple shoots & $\begin{array}{l}\text { Ghive, et al., } \\
\left(2006^{b}\right)\end{array}$ \\
\hline 24 & Momordica dioica & Node & $\begin{array}{l}\text { MS + BAP }(0.6 \mu \mathrm{m})+ \\
\text { Casein hydrolysate }(200)\end{array}$ & $\begin{array}{l}\text { Assessedgenetic } \\
\text { stability by RAPD }\end{array}$ & Rai, et al., (2012) \\
\hline 25 & Cucumis melo $L$. & Cotyledon & $\begin{array}{l}\mathrm{MS}+2,4-\mathrm{D}(5)+\mathrm{TDZ} \\
(0.1)\end{array}$ & $\begin{array}{l}\text { Somatic } \\
\text { embryogenesis }\end{array}$ & $\begin{array}{l}\text { Grey, et al., } \\
(1993)\end{array}$ \\
\hline 26 & Cocciniaabyssinica & Leaf & $\begin{array}{l}5 \% \quad \mathrm{NaOC} \text { with } 10 \\
\text { Minutes }\end{array}$ & Sterilization & $\begin{array}{l}\text { Guma, et al., } \\
(2015)\end{array}$ \\
\hline 27 & Lagenariasiceraria & Cotyledon & $\begin{array}{l}\mathrm{MS}+\mathrm{BAP}(3)+\mathrm{AgNO}_{3} \\
(0.5)\end{array}$ & $\begin{array}{l}\mathrm{AgNO}_{3} \text { derived } \\
\text { plants are diploid }\end{array}$ & Han, et al., (2004) \\
\hline 28 & Benincasahispida & Shoot tip & $\mathrm{MS}+\mathrm{BAP}(1.5)$ & Full plantlet in soil & $\begin{array}{l}\text { Haque, et al., } \\
(2008)\end{array}$ \\
\hline 29 & Lagenariasiceraria & stem & $\begin{array}{l}\mathrm{MS}+\mathrm{BAP}(2.0)+\mathrm{NAA} \\
(0.5)\end{array}$ & Full plantlet in soil & Hasbullah (2017) \\
\hline 30 & Cucumis sativus $L$. & Cotyledon & $\mathrm{MS}+\mathrm{BAP}(2.5-5 \mu \mathrm{m})$ & Multiple shoots & $\begin{array}{l}\text { Hisajima and Arai } \\
\text { (1989) }\end{array}$ \\
\hline 31 & Momordica dioica & Cotyledon & $\begin{array}{l}\text { MS + BAP }(2.0)+\text { NAA } \\
(0.5)\end{array}$ & Organogenesis & $\begin{array}{l}\text { Hoque. et al., } \\
(2000)\end{array}$ \\
\hline 32 & Momordica dioica & $\begin{array}{l}\text { Immature } \\
\text { embryo }\end{array}$ & $\begin{array}{l}\mathrm{MS}+\mathrm{IBA}(10.8)+\mathrm{NAA} \\
(1.08)+\mathrm{GA}_{3}(0.54)\end{array}$ & Full plantlet in soil & $\begin{array}{l}\text { Hoque, et al., } \\
\text { (2007). }\end{array}$ \\
\hline 33 & Cucurbita maxima & Node & $\mathrm{MS}+\mathrm{BAP}(2.0)$ & Full plantlet in soil & $\begin{array}{l}\text { Hoque, et al., } \\
\text { (2008) }\end{array}$ \\
\hline 34 & Cucumis melo L. & Shoot tip & $\begin{array}{l}\mathrm{MS}+\mathrm{BAP}(1.0)+\mathrm{IBA} \\
(0.1)+\mathrm{GA}_{3}(0.3)\end{array}$ & Full plantlet in soil & $\begin{array}{ll}\text { Huda } & \text { and } \\
\text { Sikdar(2006) }\end{array}$ \\
\hline 35 & Cucumis sativus $L$. & Cuttings & MS + Orange juice & Callus & $\begin{array}{l}\text { Ikram-ulhaq, } \\
\text { al., (2013) }\end{array}$ \\
\hline 36 & Momordica dioica & Node & $\mathrm{MS}+\mathrm{BAP}(1.0)+\mathrm{NAA}$ & Full plantlet with & Jadhav (2015) \\
\hline
\end{tabular}




\begin{tabular}{|c|c|c|c|c|c|}
\hline & & & $(0.2)$ & $\begin{array}{l}\text { Genotypes } \\
\text { response }\end{array}$ & \\
\hline 37 & Momordica dioica & Node & $\mathrm{MS}+\mathrm{BAP}(1.5)$ & Full plantlet in soil & Jamathia (2016) \\
\hline 38 & Cucumis sativus $L$. & Stem & $\begin{array}{l}\mathrm{MS}+\mathrm{BAP}(0.5)+\mathrm{NAA} \\
(1.0)\end{array}$ & Callus & $\begin{array}{l}\text { Jesmine and Mian } \\
\text { (2016) }\end{array}$ \\
\hline 39 & Momordica dioica & Node & $\begin{array}{l}\mathrm{MS}+\mathrm{BAP}(1.0)+\mathrm{NAA} \\
(1.0)\end{array}$ & Full plantlet in soil & Kapadia (2018) \\
\hline 40 & Momordica dioica & Cotyledon & $\mathrm{MS}+\mathrm{BAP}(1.5)$ & Full plantlet in soil & Karim (2011) \\
\hline 41 & Momordica dioica & Cotyledon & $\mathrm{MS}+\mathrm{BAP}(1.0)$ & Full plantlet in soil & Karim (2013) \\
\hline 42 & Momordica dioica & Cotyledon & $\mathrm{MS}+\mathrm{BAP}(1.0)$ & $\begin{array}{l}\text { Plantlet } \\
\text { regenerated from } \\
\text { calli }\end{array}$ & $\begin{array}{l}\text { Karim and Ullah } \\
\text { (2011) }\end{array}$ \\
\hline 43 & Momordica dioica & Internode & $\begin{array}{l}\mathrm{MS}+\mathrm{BAP}(0.1)+\mathrm{NAA} \\
(0.1)+\text { Sucrose }(30 \mathrm{~g} / \mathrm{l} \\
\mathrm{w} / \mathrm{v})\end{array}$ & $\begin{array}{l}\text { Somatic } \\
\text { embryogenesis }\end{array}$ & $\begin{array}{l}\text { Karim and } \\
\text { Ahamad(2010) }\end{array}$ \\
\hline 44 & Benincasahispida & Shoot tip & $\begin{array}{l}\mathrm{MS}+\mathrm{BAP}(1.5)+\mathrm{GA}_{3} \\
(0.2)\end{array}$ & Full plantlet in soil & $\begin{array}{l}\text { Kausar et al., } \\
(2013)\end{array}$ \\
\hline 45 & $\begin{array}{l}\text { Trichosanthescucumerina } \\
\text { L. }\end{array}$ & $\begin{array}{l}\text { Cotyledonary } \\
\text { node }\end{array}$ & $\begin{array}{l}\text { Kinetin }(0.1) \text { and BAP } \\
(2.0)\end{array}$ & Full plantlet in soil & $\begin{array}{l}\text { Kawale and } \\
\text { Choudhary (2009) }\end{array}$ \\
\hline 46 & Cucumis melo $L$. & Node & $\mathrm{MS}+\mathrm{BAP}(8.0)$ & Full plantlet in soil & $\begin{array}{l}\text { Keng and Hoong } \\
(2005)\end{array}$ \\
\hline 47 & Citrullus lanatus & Shoot tip & $\begin{array}{l}\mathrm{MS}+\mathrm{BAP}(5.0)+\mathrm{IAA} \\
(0.1)\end{array}$ & Full plantlet in soil & $\begin{array}{l}\text { Khalekuzzama, } \\
\text { et al.(2012) }\end{array}$ \\
\hline 48 & Citrullus lanatus & Cotyledon & $\mathrm{MS}+2,4-\mathrm{D}(1.0)$ & Callus & $\begin{array}{l}\text { Khatun et al., } \\
\left(2010^{\mathrm{a}}\right)\end{array}$ \\
\hline 49 & Citrullus lanatus & Node & $\begin{array}{l}\mathrm{MS}+\mathrm{BAP}(1.0)+\mathrm{NAA} \\
(0.2)\end{array}$ & Full plantlet in soil & $\begin{array}{l}\text { Khatun et al., } \\
\left(2010^{b}\right)\end{array}$ \\
\hline 50 & Cuсumis sativus $L$. & $\begin{array}{l}\text { Stem } \\
\text { fragments }\end{array}$ & MS + Kinetine $(6.0 \mu \mathrm{m})$ & $\begin{array}{l}\text { Flower and pollen } \\
\text { production }\end{array}$ & $\begin{array}{l}\text { Kiełkowska and } \\
\text { Havey (2011) }\end{array}$ \\
\hline 51 & Cucurbita ficifolia & Cotyledon & $\begin{array}{l}\text { MS + zeatin }(1.0)+\text { IAA } \\
(0.1)\end{array}$ & Full plantlet in soil & Kim et al., (2010) \\
\hline 52 & Trichosanthesdioica & Node & $\begin{array}{l}\mathrm{MA}+\mathrm{BAP}(2.0)+\mathrm{NAA} \\
(0.3)\end{array}$ & Full plantlet in soil & $\operatorname{Komal}\left(2011^{\mathrm{a}}\right)$ \\
\hline 53 & Trichosanthesdioica & Node & $\mathrm{MS}+\mathrm{BAP}(2.5)$ & Callus & $\operatorname{Komal}\left(2011^{b}\right)$ \\
\hline 54 & Trichosanthesdioica & Node & $\begin{array}{l}\text { Semi solid MS } \\
\text { Coconut milk }(15 \%)\end{array}$ & Full plantlet in soil & $\operatorname{Komal}\left(2011^{c}\right)$ \\
\hline 55 & Citrullus lanatus & Cotyledon & $\begin{array}{l}\text { MS + BAP (1) + coconut } \\
\text { water }(10 \%) \text {. }\end{array}$ & Organogenesis & $\begin{array}{l}\begin{array}{l}\text { Krug, } \\
(2005)\end{array}\end{array}$ et al., \\
\hline 56 & Momordica dioica & Node & $\begin{array}{l}\mathrm{MSHP}+\mathrm{AdSO}_{4}(80 \\
\text { ppm })+\mathrm{BAP}(10 \mathrm{ppm})+ \\
\mathrm{IBA}(5 \mathrm{ppm})+\text { myo- } \\
\text { inositol }(100)+\text { Agar } \\
\text { agar }(0.8 \%)+\text { Sucrose } \\
(3 \%)\end{array}$ & Full plantlet in soil & Kulkarni (1999) \\
\hline 57 & Cucumis melo $L$. & Cotyledon & $\mathrm{MS}+\mathrm{BA}(2.0)+\mathrm{IAA}$ & Full plantlet in soil & Li, et al., (2011) \\
\hline
\end{tabular}




\begin{tabular}{|c|c|c|c|c|c|}
\hline & & & $(0.2)$ & & \\
\hline 58 & Cucurbita maxima & Shoot tip & $\mathrm{MS}+\mathrm{BAP}(3.0)$ & Full plantlet in soil & Mahazabin (2008) \\
\hline 59 & Trichosanthesdioica & Cotyledon & $\mathrm{MS}+\mathrm{BAP}(1.0)$ & Full plantlet in soil & $\begin{array}{l}\text { Malex, et al., } \\
(2010)\end{array}$ \\
\hline 60 & Cucumis angurea & Node & $\begin{array}{l}\mathrm{MS}+\mathrm{BAP}(1)+\mathrm{NAA} \\
(0.2)+\mathrm{L} \text { - glutamine }(20)\end{array}$ & Full plantlet in soil & Margareate (2014) \\
\hline 61 & Cucumis sativus $L$. & Shoot tip & $\mathrm{MS}+\mathrm{BAP}(0.4 \mu \mathrm{m})$ & Full plantlet in soil & $\begin{array}{l}\text { Mohammadi and } \\
\text { Siveritepe (2007) }\end{array}$ \\
\hline 62 & Luffa acutangula & Leaf & $2,4-\mathrm{D}+\mathrm{TDZ}-(2.0)$ & Callusogenesis & $\begin{array}{l}\text { Moideen and } \\
\text { Prabha (2013) }\end{array}$ \\
\hline 63 & Luffa acutangula & Petiole & $\mathrm{MS}+2,4-\mathrm{D}+\mathrm{TDZ}(1.5)$ & Callus & $\begin{array}{l}\text { Moideen and } \\
\text { Prabha (2014) }\end{array}$ \\
\hline 64 & Momordica dioica & Node & $\begin{array}{l}\mathrm{MS}+2,4-\mathrm{D}(2.0)+\mathrm{BAP} \\
(1.0)\end{array}$ & Organogenesis & $\begin{array}{l}\text { Mustapha, et al., } \\
\text { (2012) }\end{array}$ \\
\hline 65 & Momordica dioica & Node & $\begin{array}{l}\text { MS + BAP (2.0) + L- } \\
\text { glutamic (2.0) }\end{array}$ & $\begin{array}{l}\text { Callus and shoot } \\
\text { buds }\end{array}$ & $\begin{array}{l}\text { Mustapha, et al., } \\
\text { (2013) }\end{array}$ \\
\hline 66 & Momordica dioica & Cotyledon & $\begin{array}{l}\mathrm{MS}+\mathrm{BAP}(1.0)+\mathrm{NAA} \\
(0.1)\end{array}$ & Multiple shoots & $\begin{array}{l}\mathrm{Nabi}, \\
\left(2002^{\mathrm{a}}\right)\end{array}$ et al., \\
\hline 67 & Momordica dioica & Cotyledon & $\begin{array}{l}\mathrm{MS}+\mathrm{BAP}(1.0)+\mathrm{NAA} \\
(0.1)\end{array}$ & Organogenesis & $\begin{array}{l}\mathrm{Nabi} \\
\left(2002^{\mathrm{b}}\right)\end{array}$ et al., \\
\hline 68 & Cucumis sativus $L$. & Cotyledon & $\begin{array}{lr}\begin{array}{l}\text { Kanamycin } \\
\text { and green }\end{array} & \text { resistance } \\
\text { protein } & (\mathrm{GFP}) \\
\text { fluorescence, } & \end{array}$ & $\begin{array}{l}\text { Genetic } \\
\text { transformation }\end{array}$ & $\begin{array}{l}\text { Nanasato, et al., } \\
\text { (2013) }\end{array}$ \\
\hline 69 & Cucurbita pepo & Hypocotyle & MS + Thidiazuron $(0.5)$ & Full plantlet in soil & Pal, et al., (2007) \\
\hline 70 & Cucumis melo $L$. & Node & $\mathrm{MS}+\mathrm{BAP}(2.0)$ & Full plantlet in soil & $\begin{array}{l}\text { Parvin et al., } \\
(2013)\end{array}$ \\
\hline 71 & Momordica dioica & Node & $\begin{array}{l}\mathrm{MS}+\mathrm{NB} 6+\mathrm{BAP} \\
(0.5+0.5)\end{array}$ & $\begin{array}{l}\text { Shoot } \\
\text { multiplication } \\
\text { from callus }\end{array}$ & $\begin{array}{l}\text { Patel and Kalpesh } \\
\text { (2015) }\end{array}$ \\
\hline 72 & Cucurbita pepo & Cotyledon & $\begin{array}{l}2 ., 4,5-\mathrm{T}(4.7 \mu \mathrm{m})+\mathrm{BAP} \\
(4.0 \mu \mathrm{m})+\text { Kinetine } \\
(0.5 \mu \mathrm{m})\end{array}$ & Somatic embryos & Paula (1992) \\
\hline 73 & Cucurbita pepo & Shoot tip & $\begin{array}{l}\mathrm{MS}+2,4,5-\mathrm{T}(1.2)+ \\
\mathrm{BAP}(0.8)+\text { Kinetin } \\
(0 . \mathrm{I})\end{array}$ & $\begin{array}{l}\text { Somatic } \\
\text { embryogenesis }\end{array}$ & $\begin{array}{l}\text { Paula, et al., } \\
(1990)\end{array}$ \\
\hline 74 & Cucumis melo L. & Leaf node & $\mathrm{MS}+\mathrm{BAP}(1.0)$ & Full plantlet in soil & $\begin{array}{l}\text { Rahaman, et al., } \\
\text { (2012) }\end{array}$ \\
\hline 75 & Momordica sahyadrica & Seedlings & $\mathrm{MS}+\mathrm{BAP}$ & $\begin{array}{l}\text { Full plantlet in soil } \\
\text { and conservation }\end{array}$ & $\begin{array}{l}\text { Rajashekharan, } \\
\text { et al., (2012) }\end{array}$ \\
\hline 76 & Momordica dioica & Leaf & $\begin{array}{l}\mathrm{MS}+2,4-\mathrm{D}(2.0)+\mathrm{BAP} \\
(2.0)\end{array}$ & $\begin{array}{l}\text { Molecular } \\
\text { confirmation of } \\
\text { sex }\end{array}$ & Raju et al., (2015) \\
\hline 77 & Citrullus colocynth & Cotyledon & $\begin{array}{l}\mathrm{MS}+\mathrm{IAA}(2.0)+\mathrm{IBA} \\
(1.5)\end{array}$ & Rhizogenesis & $\begin{array}{l}\text { Ram and Shashtri } \\
\text { (2015) }\end{array}$ \\
\hline
\end{tabular}




\begin{tabular}{|c|c|c|c|c|c|}
\hline 78 & Cucumis melo $L$. & Cotyledon & $\begin{array}{l}\mathrm{MS}+\mathrm{IBA}(5.0 \mu \mathrm{M})+ \\
\mathrm{BAP}(5.0 \mu \mathrm{M})+25-29^{\circ} \mathrm{C} \\
+\quad \text { light intensity } \\
\left.30 \mu \mathrm{molm}^{-2} \mathrm{~s}^{-2}\right)\end{array}$ & $\begin{array}{l}\text { Factors } \\
\text { influence }\end{array}$ & $\begin{array}{l}\text { Randall, et al., } \\
\text { (1989) }\end{array}$ \\
\hline 79 & Momordica charantia & Leaf & $\mathrm{MS}+\mathrm{BAP}(1.5)$ & Callusogenesis & $\begin{array}{l}\text { Saima malik, et } \\
\text { al., (2007) }\end{array}$ \\
\hline 80 & Cucumis sativus $L$. & Shoot tip & $\mathrm{MS}+\mathrm{BAP}(1.0)$ & Full plantlet in soil & $\begin{array}{l}\text { Sangeetha, et al., } \\
\text { (2011) }\end{array}$ \\
\hline 81 & $\begin{array}{l}\text { Interspecific Cucurbita } \\
\text { hybrid }\end{array}$ & Shoot tip & $\mathrm{MS}+\mathrm{BAP}(3.0)$ & Full plantlet in soil & $\begin{array}{l}\text { Sarowar, et al., } \\
(2003)\end{array}$ \\
\hline 82 & Cuсumis trigonus & Leaf & $\begin{array}{l}\mathrm{MS}+\mathrm{BA}(1.0)+\mathrm{IAA} \\
(0.25)\end{array}$ & Full plantlet in soil & $\begin{array}{l}\text { Satapathy et al., } \\
\text { (2014) }\end{array}$ \\
\hline 83 & Citrullus colocynth & Leaf & $\begin{array}{l}\mathrm{MS}+2,4-\mathrm{D}(1.5)+\mathrm{BAP} \\
(1.0)\end{array}$ & Callus & $\begin{array}{l}\text { Savitha, et al., } \\
\text { (2010) }\end{array}$ \\
\hline 84 & Cucumis sativus $L$. & Hypocotyle & $\begin{array}{l}\text { MS + Sucrose }(87.64 \mu \mathrm{M}) \\
+\operatorname{agar}(0.8 \%)+2,4-\mathrm{D} \\
(3.62 \mu \mathrm{M})+\text { BAP } \\
(2.22 \mu \mathrm{M})\end{array}$ & genesis & $\begin{array}{l}\text { Selvaraj, et al., } \\
(2006)\end{array}$ \\
\hline 85 & Citrullus colocynth & Leaf & $\begin{array}{l}\mathrm{MS}+\mathrm{Kn}(2.0)+\mathrm{TDZ} \\
(1.0)\end{array}$ & Callusogenesis & $\begin{array}{l}\text { Shashtree, et al., } \\
\text { (2014) }\end{array}$ \\
\hline 86 & Momordica dioica & Node & $\begin{array}{l}\mathrm{MS}+\mathrm{BAP}(2.0)+\mathrm{IAA} \\
(0.1)\end{array}$ & Full plantlet in soil & $\begin{array}{l}\text { Shekhawat, et al., } \\
\text { (2011) }\end{array}$ \\
\hline 87 & Luffa cylindrica & Cotyledon & $\begin{array}{l}\text { MS salts + B5 + BAP } \\
(10 \mu \mathrm{M})\end{array}$ & $\begin{array}{l}\text { Resistant GUS } \\
\text { ( } \beta \text {-Glucuronidase) }\end{array}$ & $\begin{array}{l}\text { Singh, et al., } \\
(2011)\end{array}$ \\
\hline 88 & Trichosanthesdioica & Leaf & $\begin{array}{l}\text { MS + BAP }(0.5)+2,4-D \\
(0.5)\end{array}$ & Callus & $\begin{array}{l}\begin{array}{l}\text { Sourab, et al., } \\
(2017)\end{array}\end{array}$ \\
\hline 89 & Luffa cylindrica & Leaf & $\begin{array}{l}\mathrm{MS}+\mathrm{BAP}(1.5)+\mathrm{NAA} \\
(1.0)\end{array}$ & Callus & $\begin{array}{l}\text { Srivastava and } \\
\text { Roy (2012) }\end{array}$ \\
\hline 90 & Momordica charantia & Node & $\begin{array}{l}\mathrm{MS}+\mathrm{BAP}(2.0)+\mathrm{NAA} \\
(0.2)\end{array}$ & Full plantlet in soil & $\begin{array}{l}\begin{array}{l}\text { Sultana, et al., } \\
(2003)\end{array}\end{array}$ \\
\hline 91 & Citrullus lanatus & Leaf & $\mathrm{MS}+2,4-\mathrm{D}(2.5)$ & $\begin{array}{l}\text { Organogenesis } \\
\text { callus }\end{array}$ & $\begin{array}{l}\begin{array}{l}\text { Sultana, et al., } \\
(2004)\end{array}\end{array}$ \\
\hline 92 & Momordica charantia & Node & $\begin{array}{l}\mathrm{MS}+\mathrm{BAP}(2)+\mathrm{NAA} \\
(0.2)+\text { Sucrose } 30 \mathrm{gl}^{-1}+ \\
\text { Agar } 7.0 \mathrm{gl}^{-1}+\mathrm{pH}(5.5- \\
6.0)\end{array}$ & $\begin{array}{l}\text { Effects of sucrose, } \\
\text { agar } \mathrm{pH}\end{array}$ & $\begin{array}{l}\begin{array}{l}\text { Sultana, et al., } \\
(2005)\end{array}\end{array}$ \\
\hline 93 & Citrullus lanatus & Cotyledon & $\mathrm{MS}+\mathrm{BAP}(20.0 \mu \mathrm{M})$ & Full plantlet in soil & $\begin{array}{l}\text { Suratman, et al., } \\
(2009)\end{array}$ \\
\hline 94 & Momordica dioica & Leaf & $\begin{array}{l}\mathrm{MS}+\mathrm{BAP}(3.0)+\mathrm{NAA} \\
(0.5)\end{array}$ & Organogenesis & $\begin{array}{l}\begin{array}{l}\text { Swamy, et al., } \\
(2015)\end{array}\end{array}$ \\
\hline 95 & Momordica balsamina & Node & $\mathrm{MS}+\mathrm{BAP}(1.0)$ & Full plantlet in soil & $\begin{array}{l}\text { Thakur, et al., } \\
\text { (2011) }\end{array}$ \\
\hline 96 & Momordica charantia & Leaf & $\mathrm{MS}+2,4-\mathrm{D}(1.0)$ & Embryogenesis & $\begin{array}{l}\text { Thiruvengadam, } \\
\text { et al., (2006) }\end{array}$ \\
\hline 97 & Momordica dioica & Petiole & $\mathrm{MS}+2,4-\mathrm{D}(2.2 \mu \mathrm{m})+$ & Somatic emryoids & Thiruvengadam, \\
\hline
\end{tabular}




\begin{tabular}{|c|c|c|c|c|c|}
\hline & & & L- glutamine $(0.5 \mu \mathrm{m})$ & & et al., (2007) \\
\hline 98 & Momordica dioica & $\begin{array}{l}\text { Encapsulated } \\
\text { Shoot tip }\end{array}$ & $\begin{array}{l}\text { MS }(0.7 \%+\text { agar } \\
\text { solidified })+ \text { BAP } \\
(0.5 \mu \mathrm{m})\end{array}$ & $\begin{array}{l}\text { Full plant let in } \\
\text { soil } \\
\text { variation }\end{array}$ & $\begin{array}{l}\text { Thiruvengadam, } \\
\text { et al., }\left(2012^{\mathrm{a}}\right)\end{array}$ \\
\hline 99 & Momordica charantia & Petiole & $\begin{array}{l}\mathrm{MS} \text { and Gamboge }+ \\
\text { NAA }(3.0 \mu \mathrm{m})+\text { TDZ } \\
(1.0 \mu \mathrm{m})+\text { Putrecine } \\
(1.0 \mu \mathrm{m})\end{array}$ & $\begin{array}{l}\text { Plantlet from } \\
\text { organogenesis }\end{array}$ & $\begin{array}{l}\text { Thiruvengadam, } \\
\text { et al., }\left(2012^{\mathrm{b}}\right)\end{array}$ \\
\hline 100 & Momordica dioica & Leaf & $\begin{array}{l}\mathrm{MS}+2,4-\mathrm{D}(3.3 \mu \mathrm{m})+ \\
\text { Putrescine }(0.5 \mu \mathrm{m})\end{array}$ & $\begin{array}{l}\text { Somatic } \\
\text { embryogenesis }\end{array}$ & $\begin{array}{l}\text { Thiruvengadam, } \\
\text { et al., (2013) }\end{array}$ \\
\hline 101 & Benincasahispida & Cotyledon & $\begin{array}{l}\mathrm{MS}+\mathrm{BAP}(1-6 \mu \mathrm{M})+ \\
\mathrm{NAA}, 0.2 \text { and } 0.5 \mu \mathrm{M}\end{array}$ & Full plantlet in soil & $\begin{array}{l}\text { Thomas, et al., } \\
\text { (2004) }\end{array}$ \\
\hline 102 & Luffa acutangula & Cotyledon & $\begin{array}{l}\text { MS + BAP }(1.0)+\text { Zeatin } \\
(0.2)+\text { NAA }(0.2)+ \\
2,4-\mathrm{D}(0.6)+\text { Picloram } \\
(0.1)+\text { AdS }(20)\end{array}$ & Full plantlet in soil & $\begin{array}{l}\text { Umamaheshwari, } \\
\text { et al.(2014) }\end{array}$ \\
\hline 103 & Cuсumis sativus $L$. & Leaf & $\begin{array}{l}\mathrm{MS}+2,4-\mathrm{D}(5)+\mathrm{TDZ} \\
(0.1)\end{array}$ & $\begin{array}{l}\text { Somatic } \\
\text { embryogenesis }\end{array}$ & $\begin{array}{l}\text { Usman, et al., } \\
\text { (2011) }\end{array}$ \\
\hline 104 & Cucurbita moschata & Cotyledon & $\begin{array}{l}\text { Callus induction medium } \\
(\mathrm{CIM})+2,4-\mathrm{D}(0.5 \text { or } \\
3.5)\end{array}$ & $\begin{array}{l}\text { Somatic } \\
\text { embryogenesis }\end{array}$ & $\begin{array}{l}\text { Valdez-Melara, } \\
\text { et al., (2009) }\end{array}$ \\
\hline 105 & Citrullus lanatus & Shoot tip & $\mathrm{MS}+\mathrm{BAP}(0.5)$ & Full plantlet in soil & $\begin{array}{l}\text { Vedat, et al., } \\
(2002)\end{array}$ \\
\hline 106 & Luffa acutangula & Petiole & $\begin{array}{l}\mathrm{MS}+\mathrm{BAP}(2.0)+\mathrm{NAA} \\
(0.2)\end{array}$ & $\begin{array}{l}\text { genetic } \\
\text { by IISR }\end{array}$ & $\begin{array}{l}\text { Vellivella, et al., } \\
\text { (2016) }\end{array}$ \\
\hline 107 & $\begin{array}{l}\text { Cucumis melo var } \\
\text { utillisimus }\end{array}$ & Node & $\begin{array}{l}\text { MS + BAP }(1.0)+ \\
\text { Adenine sulphate }(15)\end{array}$ & Multiple shoots & $\begin{array}{l}\text { Venkateshawaralu, } \\
\text { et al.(2010) }\end{array}$ \\
\hline 108 & Cucumis melo L. & Shoot tip & $\begin{array}{l}\mathrm{MS}+\mathrm{IAA}(0.5)+\mathrm{BAP} \\
(2.0)\end{array}$ & Multiple shoots & $\begin{array}{l}\text { Venkateshwaralu } \\
\text { (2012) }\end{array}$ \\
\hline 119 & Momordica charantia & Node & $1 / 2 \mathrm{MS}+\mathrm{BAP}(0.5)$ & Full plantlet in soil & $\begin{array}{l}\text { Verma, et al., } \\
\text { (2014) }\end{array}$ \\
\hline 110 & Cucumis figarei & Cotyledon & $\begin{array}{l}\mathrm{MS}+\mathrm{BAP}(1.0)+\mathrm{ABA} \\
(1.0 \text { or } 2.0)\end{array}$ & Full plantlet in soil & $\begin{array}{l}\text { Yutaka, et al., } \\
\text { (1998) }\end{array}$ \\
\hline 111 & Cucumis metuliferus & Cotyledon & $\begin{array}{l}\text { MS +BAP (1.0) + IAA. } \\
(0.2)\end{array}$ & Full plantlet in soil & $\begin{array}{l}\text { Yutaka et al., } \\
\text { (1998) }\end{array}$ \\
\hline 112 & Luffa acutangula & Cotyledon & $\begin{array}{l}\mathrm{MS}+\mathrm{BAP}(1.5)+\mathrm{NAA} \\
(1.0)\end{array}$ & Organogenesis & $\begin{array}{l}\text { Zohura, et al., } \\
\text { (2013) }\end{array}$ \\
\hline
\end{tabular}

The use of $30 \mathrm{~g} / \mathrm{l}$ sucrose gave $100 \%$ shoot proliferation with $5.1 \pm 0.8$ shoots having length of $5.6 \pm 0.4 \mathrm{~cm}$.MS medium having $7 \mathrm{~g} / \mathrm{l}$ agar showed $100 \%$ frequency in shoot proliferation. Highest frequency of multiple shoot was regenerated on MS medium containing $1.0 \mathrm{mgl}^{-}$ ${ }^{1} \mathrm{BAP}+0.2 \mathrm{mgl}^{-1} \mathrm{NAA}+\mathrm{L}$ - glutamine $\left(20 \mathrm{mgl}^{-1}\right)$ and elongation of shoots were achieved by adding $\mathrm{GA}_{3}(0.5 \mathrm{mg} / \mathrm{l})$ in Cucumis anguria (Margareate 2014). In female plants of Momordica dioicabud breaking occurrence of nodal explants was noticed in very low concentration of IAA $(0.1 \mathrm{mg})$ with BAP (2.0mg) (Shekhawat et al., 2011). Kulkarni (1999) conducted micropropagation studies in Kartoli by using nodal segment as an explant 
and developed a proper method of in-vitro regeneration and multiplication. MSHP + $80 \mathrm{ppm} \mathrm{AdSO}_{4}+10 \mathrm{ppm} \mathrm{BA}+5 \mathrm{ppm} \mathrm{IBA}$ $+100 \mathrm{mg}$ myo-inositol $+0.8 \%$ Agar agar $+3 \%$ sucrose gave good results $(75 \%)$. The same medium gave the maximum multiple shoots per culture $(81 \pm 1.28)$ at the end of $4^{\text {th }}$ subculture. It was found that the nodal segment cultures of spine gourd initiated maximum rooting response $(86.66 \%)$ to the medium, MS basal+ 3 ppm NAA $+0.8 \%$ Agar agar $+3 \%$ sucrose + $0.2 \%$ activated charcoal. Among the different potting mixture compositions tried for hardening of the in-vitro developed plantlets vermiculite alone gave maximum $(77.33 \%)$ survival and the lowest survival was observed in potting mixture with FYM $(20 \%)$ alone. A minimal medium and protocol has been formulated to reduce the cost and time period of micropropagated raised plants of Trichosanthesdioica Roxb. Semi solid MS with $15 \%$ coconut water showed the highest percentage of plantlet regeneration (99\%) and rhizogenesis was observed when explants were cultured on this medium within 5-6 days, followed by shoot formation in 8-10 days (Komal 2011 ${ }^{\mathrm{c}}$ ).

\section{Cotyledon}

In micropropagation cotyledons play a vital role in giving the successful plantlets. In thisregard, most of the scientist used the BAP alone or in combination with the other growth hormone for regeneration of plant. As per the opinions of most of the investigators BAP in the range 1.0, $1.5,2.0$ showed the best results for optimum plant regeneration (Karim and Ullah 2011, Malex et al., 2010, Zohura et al., 2013, Li et al., 2011). In Luffaacutangula, by using cotyledon as explant, organogenesis was found best on media supplemented with BAP $1.5 \mathrm{mg} / \mathrm{l}$ and NAA $1.0 \mathrm{mg} / \mathrm{l}$ (Zohura et al., 2013). When watermelon is treated with the lower concentrations of BAP $(20 \mu \mathrm{M})$ the highest mean number of shoots obtained was $(9.83 \pm 0.81)$, whereas another scientist used cotyledons excised from 7-day-old aseptic seedlings the Sugar baby variety of Citrullus lunatus Thumb. Matsum and Nakai, the maximum number of shoots were recorded on $\mathrm{MS}+\mathrm{BAP} 3.0 \mu \mathrm{M}+2 \mathrm{iP} 3.0 \mu \mathrm{M}$ and $\mathrm{MS}+\mathrm{BA}$ $3.0 \mu \mathrm{M}+$ IAA $3.0 \mu \mathrm{M}$. Finally, $55 \%$ plants showed success in field (Suratman. 2009, Chaturvedi and Bhantnagar. 2001). Arekar (2012) used the decoated seeds of Momordica dioica for shoot regeneration and got maximum number of shoots in 7-8 weeks on $4.44 \mu \mathrm{M}$ and $8.88 \mu \mathrm{M}$ BAP. The rooting was recorded within 45 days when supplemented with $0.049 \mathrm{mM}$ IBA. Indole-3 Acetic acid is used by the several scientists in Cucurbita ficifolia, Citrullus lanatus, Citrullus colocynth for getting plantlet but use of MS + IAA (2.0) + IBA (1.5) in Citrullus colocynthreported rhizogenesis (Rama Krishna and Shashtri 2015). In addition to this, MS + IAA (0.1) + zeatin (1.0) was found to be efficient for shoot regeneration in Cucurbita ficifolia (Kim et al., 2009).

Randall et al (1989) used cotyledonary explants of Cucumis melo in MS medium fortified with $5 \mu \mathrm{M}$ IBA and $5 \mu \mathrm{M}$ BAP and incubated at 25$29^{\circ} \mathrm{C}$ under low light intensity of $5-30 \mu$ molm $^{-2} \mathrm{~s}^{-}$ ${ }^{2}$. They observed that the presence of ABA significantly enhanced the number of explants producing shoot buds. It was also observed that seedling age, genotype, temperature and light intensity affected bud initiation. The addition of various phytohormones like thidiazuron, gibberellic acid or silver nitrate to regeneration medium was not noticed in improving, either bud initiation or shoot regeneration.

\section{Somatic embryogenesis}

Plant regeneration via somatic embryogenesis follows the initiation of embryonic culture, proliferation of embryonic culture, prematuration of somatic embryo, maturation of somatic embryo and plant development on nonspecific media. So many interested scientists were worked on plant regeneration by using somatic embryogenesis. High frequency somatic embryogenesis(3.3 somatic embryos) was noticed in Cucumis melo on 2, 4-D at 5 $\mathrm{mg} / \mathrm{l}$ and TDZ at $0.1 \mathrm{mg} / \mathrm{l}$ while $3 \%$ sucrose was found to be highly significant in embryo 
induction and development (Gray et al., 1993). RAPD markers viz; OP-G14, OP-C10, OP-Y03, OP-H05 and OP-AT01were used to evaluate the genetic stability of regenerants of Cucumis sativus plants obtained through somatic embryogenesis and found that there are no significant visual differences between the somatic embryo plants and F1 hybrids (Elmeer et al., 2009). Immature embryo and immature cotyledon of Momordica dioicawere used to get higher percentage of somatic regeneration but immature embryo showed best response than immature cotyledon for shoot proliferation onMS + IBA (10.8) + NAA (1.08) + GA3 (0.54) (Hoque et al., 2007). 2, 4-dichloro phenoxy acetic acid is one of the major auxin in inducing somatic embryos as reported by many persons who worked on this one and in all the cases 2, 4-D $1.0 \mathrm{mgl}^{-1}$ and $2.0 \mathrm{mgl}^{-1}$ in single or in combination with other growth regulators like BAP, TDZ were also used to get somatic embryos (Thiruvengadam et al., 2006, Raju et al., 2015). Hisajima and Arai (1989) reported that BAP $(2.5-5 \mu \mathrm{m})$ in Cucumis sativus by using cotyledons as explant gave multiple shoots. Raju et al., (2005) worked on molecular sex confirmation in Momordica dioicaby the plant regenerated from leaf callus of somatic embryogenesis at $\mathrm{MS}+2$, 4-D (2.0) + BAP (2.0).Maximum amount of callus $(94.16 \%)$ was inducedon leaf disc explants of cucumber on MS medium fortified with 2, 4-D @ $2.0 \mathrm{mg} / 1$. Callus induced from leaf disc explants at higher level of 2, 4-D $\left(5 \mathrm{mgl}^{-1}\right)$ yielded the highest percentage of embryo formation i.e. $23 \%$ (Usman et al., 2011).Plants were regenerated from the callus of shoot tip, petiole, leaf explant, internode and nodal explants. The highest callus induction was noticed in internodal explant of teasle gourd on semi-solid MS media containing basal salts and growth regulators fortified with $1.0 \mathrm{mg}^{-1} \mathrm{BAP}, 30 \mathrm{~g} / \mathrm{l}$ (w/v) and $0.1 \mathrm{mgl}^{-1}$ NAA sucrose (Karim and Ahamad. 2010). Somatic embryogenesis was successfully achieved in Cucurbita pepo by using shoot tip and cotyledon at various combination and concentration of 2,4,5-T (1.2) $+\operatorname{BAP}(0.8)+$ Kinetin $(0.1)$ and 2.,4,5-T $(4.7 \mu \mathrm{m})+\operatorname{BAP}(4 \mu \mathrm{m})+$ kinetine $(0.5 \mu \mathrm{m})$, respectively where best callus was noticed in cotyledon derived explant (Paula et al., 1990 and Paula 1992).

Good amount of friable embryogenic callus was recorded on callus induction medium fortified with $0.5 \mathrm{mgl}^{-1}$ or $3.5 \mathrm{mgl}^{-1}$ 2, 4-D from zygotic embryos(53-56\%) and cotyledonary seedlings (70\%) derived from Cucurbita moschata cv. Sellode Oro. Among the 75 per cent of the evaluated pure lines of Cucurbita moschata, embryogenic calli induction with the frequency range from $5 \%$ to $34 \%$ were registered. Regenerated plants from micropropagation looks morphologically normal and sets the flower, fruit and seed which could germinate normally (Valdez-Melara et al., 2009). Various main cucurbits such as cucumber, watermelon, squash, and melons were studied to build a protocol for somatic embryogenesis. Out of several explants used, cotyledons and hypocotyls gave the best results. In somatic embryogenesis, genetic constitution of mother plants playeda vital role. Somatic embryos showed the abnormalities during the growth phase of plants, if they were raised from the protoplast derived cultures (Debeaujon and Branchard, 1993).

\section{Organogenesis}

Organogenesis is defined as the development of adventitious organs of plant part or primordia from the mass of undifferentiated cells which is called as callus, by the process of differentiation. The regeneration of plant or plant organs only taken place by the expression of cellular totipotency of the callus tissue. In the process of organogenesis, a good quality of callus initiation plays a vital role for the further regeneration. In most of the findings researchers had used cotyledon as an explant in various cucurbit crops. They used BAP as good callus inducing growth hormone either single or in combination with various kind of growth regulators. In allthe best callusing reports, BAP range is $1.01 .5,2.0$ and $3.0 \mathrm{mg} / \mathrm{l}$ (Krug et al., 2005, Compton and Grey. 1992, Karim, 2013, Yutaka et al., 1998, Nabi et al., 2002 ${ }^{\mathrm{b}}$, Hoque et 
al., 2000, Hasbullah, 2017, Han et al., 2004, Karim, 2011). The potentiality of watermelon callus induction and its successive regeneration from cotyledon and internode was studied by Khatun et al., $\left(2010^{\mathrm{a}}\right)$. Greenish compact callus was achieved from cotyledon on MS fortified with $1 \mathrm{mg} / \mathrm{l} 2$, 4-D within one week of inoculation. When most of the scientists in their research used the BAP more than $1.0 \mathrm{mg} / \mathrm{l}$, Vedat Pirinc et al., (2002) used the BAP at lower concentration i.e. $0.5 \mathrm{mg} / \mathrm{l}$ and got $50 \%$ more number of shoots which were higher than Kinetin@1.0 mg/l in Citrullus lanatus.

Organogenesis in water melon was studied and the best result was obtained in cotyledon segments which were taken from the proximal region. The explants were inoculated on MS medium supplemented with $1.0 \mathrm{mgl}^{-1} \mathrm{BAP}$ and $10 \%$ coconut water. It was revealed from the histological study that the organogenesis occurs directly without any callus formation on epidermal layer and sub-epidermal layers of the explants (Krug et al., 2005). In the process of organogenesis, BAP supplemented with the other growth hormones were found to be best for callusing. In this regards, many persons (Nabi et al., 2002 ${ }^{\mathrm{b}}$, Hoque et al., 2000, Hasbullah, 2017)used the BAP @ 1.0-2.0mg/l supplemented with the lower concentrations of NAA 0.1 to higher concentration of $0.5 \mathrm{mg} / \mathrm{l}$ in Momordica dioica and Lagenaria siceraria. The explants used in the study were cotyledon and stem respectively. By using cotyledon explantsin Luffa acutangula L. Roxb., multiple shoots were induced via indirect organogenesis on MS media fortified with BAP (1.0) + Zeatin $(0.2)+\mathrm{NAA}(0.2)+2$, 4-D (0.6) + Picloram $(0.1)+\mathrm{AdSo}_{4}$ (20). The average shoots per explants produced were 10.3 in 78.34 per cent of the cotyledon derived callus (Umamaheshwari et al., 2014). Maximum shoot regeneration was observed in proximal parts of cotyledons derived from 4-day-old seedlings of bottle gourd when cultured on MS medium with $3 \mathrm{mg} / \mathrm{l} \mathrm{BAP}$ and $0.5 \mathrm{mg} / \mathrm{l} \mathrm{AgNO}_{3}$ under a $16 \mathrm{hr}$ photoperiod. The diploid cultured were recorded in the most of the $\mathrm{AgNO}_{3}$ supplementation. This observation was reported by flow cytometric analysis (Han et al., 2004). The effect of commercial fruit juices was also tested for callus induction, its proliferation and plant regeneration in cucumber. The orange, apple, strawberry and red grapes were used in the place of $3 \%$ sucrose. Out of these, MS medium supplemented with Orange juice was found to be the best source of callusing as reported by Ikram-ul Haq et al., (2013). In Invitro organogenesis from hypocotyle explant of Cucumis melo var Poinsette, calli were induced on MS + Sucrose $(87.64 \mu \mathrm{M})+\operatorname{agar}(0.8 \%)+$ $2,4-\mathrm{D}(3.62 \mu \mathrm{M})+\mathrm{BAP}(2.22 \mu \mathrm{M})$ and regeneration of adventitious shoot from these calli (25 shoots per explant) were achieved on $\mathrm{MS}+8.88 \mu \mathrm{M} \mathrm{BAP}+2.5 \mu \mathrm{M}$ zeatin $+10 \%$ coconut water (Selvaraj et al., 2006). The 2, 4dichloro phenoxy acetic acid at $2.5 \mathrm{mg} / 1$ gave best callusing percentage in hypocotyle explants of Cucurbita pepo and the highest percentage of shoot regeneration $(85 \%)$ was obtained at $0.5 \mathrm{mg} / 1 \mathrm{TDZ}$, About, $70 \%$ of regenerated plantlets survived under ex-vitro conditions (Pal et al., 2007). MS + BAP $(1-6 \mu \mathrm{M})+$ NAA, 0.2 and $0.5 \mu \mathrm{M}$ was observed best response on cotyledon explant of Benincasahispida (Thomas et al., 2004).

For the production of callus, TDZ is one of the major source for callusogenesis in single or in combination. Most of the research workers used combination form of TDZ with 2,4-D and Kinetine, Best callusogenic response was observed in 2, 4-D + TDZ-2.0mg/l and MS + Kn (2.0) + TDZ (1.0) in Luffa acutangula and Citrullus colocynth respectively by using leaf as explant (Moideen and Prabha,2013 and Shashtree et al., 2014). Guma et al., (2015) conducted study to develop efficient protocol for sterilization and callus induction in Cocciniaabyssinica. Maximum number of clean explants with better survival rate $(82.5 \pm 0.5)$ was obtained when they were treated with $5 \%$ $\mathrm{NaOCl}$ for 10 minutes sterilization period and maximum amount of callus induction i.e., $80 \pm 2.0$ was achieved from the combination of $5.0 \mu \mathrm{m} \mathrm{BAP}+2$, 4-D. During the course of organogenesis, callusing is the first step to induce a good quality callus. Majority of the 
research workers, preferred to use 2,4-D either single or in combination with various growth hormones. In some investigations, best callusing range of 2,4-D reported was $0.5,1.0$, 1.5 and $2.5 \mathrm{mg} / 1$ with BAP $0.5,1.0$ and $2.0 \mathrm{mg} / 1$ in leaf explants of Momordica dioica, Citrullus lanatus, Citrullus colocynth, Trichosanthesdioica (Devendra, 2009, Sultana et al., 2004, Savitha et al., 2010,Sourab et al., 2017). Some of the scientists had used either BAP alone or BAP with IAA to get the callus followed by organogenesis. The BAP @ 1.0 and $1.5 \mathrm{mg} / \mathrm{l}$ concentrations was used in alone. When used with IAA then MS + BA (1.0) + IAA (0.25) was found best in Cucumis trigonus, Cucumis melo L. Momordica charantia. The explants used were leaf explants (Satapathy et al., 2014, Rahaman et al., 2012 and Saima malik et al., 2007). In case of Momordica dioica and Luffa cylindrica, BAP@1.0, 1.5 and $3.0 \mathrm{mg} / 1$ in combination with the NAA @ 0.1 , 0.5 and $1.0 \mathrm{mg} / \mathrm{l}$ was found to be the best source of callusing and organogenesis. In some cases, use of BAP $1.0+\mathrm{NAA} 1.0 \mathrm{mg} / \mathrm{l}$ was reported for multiple shoot regeneration from callus leaf explants (Nabi et al., 2002 ${ }^{\mathrm{a}}$, Srivastava and Roy. 2012, Swamy et al., 2015).

Coconut milk is the one of the very good organic source of growth hormones mainly cytokinins. In this regard Debnath et al., (2015) by using nodal explants of Momordica dioica and Momordica cochinchinensis media supplemented with coconut milk (15\% v/v) and 2, 4-D (2.0 $\mathrm{mg} / \mathrm{l})$ had reported highest percentage of callusing and organogenesis, in both the species. Further they added 05. mg/l BAP with agar gelled MS as a basal medium for Momordica dioicawhile in case of Momordica cochinchinensis, did not usethe BAP with agar gelled MS as basal medium. In another treatment, for Momordica dioica, coconut milk was avoided and good amount of compact and green callus was obtained on 2, 4-D (2.0) + BAP (1.0) supplemented medium (Debnath. 2013, Debnath et al., 2013, Mustapha et al., 2012). Direct organogenesis was reported in Momordica cymbalarias on BAP2.0 mg/l for shoot regeneration (Devi et al., 2017). In case of Momordica dioica, for inducing the callus and multiplication of shoot, first timeNB 6 phytohormones was used. $\mathrm{NB}_{6}+\mathrm{BAP}(0.5+$ $0.5 \mathrm{mgl}^{-1}$ ) recorded the highest percentage of shoot multiplication within 15 days of inoculation with shoot length $5.2 \pm 0.37 \mathrm{~cm}$ and shoot numbers $10 \pm 1.4$ (Patel and Kalpesh, 2015).

Addition of polyamines in culture media has enhanced the percentage of callus induction in organogenesis of bitter melon by using petiole as explant. The medium supplemented with 3.0 $\mu \mathrm{M}$ NAA, $1.0 \mu \mathrm{M}$ TDZ and $1.0 \mu$ Mputrecine induced $95.0 \%$ callus induction while regeneration of adventitious shoots from callus was achieved i.e., 53 shoots per explant on medium with $3.0 \mu \mathrm{M}$ TDZ with $1.0 \mu \mathrm{M}$ NAA and $1.0 \mu \mathrm{M}$ Spermidine (Thiruvengadam et al., 2012). Callus induction and multiplication was tried on Luffa acutangula by using node, leaf and petiole explant. Out of all explants used for experimentation, the petiole showed the best callusing percentage in 2, 4-D + TDZ - 1.5mg/l. (Moideen and Prabha. 2014).The IISR marker techniques were used to find out the clonal fidelity from the callus derived regenerated plant of Luffa acutangular. In this, 2mg/l BAP and $0.2 \mathrm{mg} / \mathrm{l}$ NAA were used for highest callus (Vellivella. 2016). The highest percentage of callus was obtained from stem explant $(89.0 \pm$ $0.75 \%)$ followed by leave $(79.05 \pm 3.28)$ in NAA and BAP but addition of 2, 4-D on growth medium had promoted the slow growth and low quality callus in cucumber (Jesmin and Mian. 2016).

\section{Other}

Homozygous doubled haploid lines (DHLs) from cucumber could be helpful to breed resistant varieties. Parthenogenic embryos are induced by irradiated pollen with Co ${ }_{60}$ gammarays at 500 gamma. The SSR markers were used to discriminate the undesirable zygotes. Chromosome doubling of haploid was done by Colchicine $500 \mu \mathrm{M}$. Selfing was done between the colchicine treated haploid plants and those plants were allowed for the perpetuation by 
seed of homozygous lines. Percentage of seed set was $90 \%$, and it was concluded that DHLs are ideal resources for genomic analyzer (Claveria et al., 2005). Rooting studies on spine gourd conducted reported that plants of healthy shoots with their own root system were able to survive and became complete plantlet. The highest percentage of rooting was obtained on IBA (1.0) (Ghive et al., 2006a).

In cell suspension culture, single or small aggregates of cells multiply while suspended in agitated liquid medium. Thiruvengadamis one of the pioneer research scientist who worked more and more on the cell suspension culture of some cucurbits to achieve somatic embryogenesis. In all his findings, he used the 2, 4-D either single or in combination with the other plant hormones. The range of 2, 4-D at $2.2 \mu \mathrm{m}$ and $2.0 \mu \mathrm{M}$ with $\mathrm{L}-$ glutamine $(0.5 \mu \mathrm{m})$ was found to be the best for somatic embryogenesis by using petiole and leaf explants in Momordica dioica and Cucumis anguria respectively. For the leaf explant of Momordica dioica, addition of putrecine $(0.5 \mu \mathrm{m})$ rather than L- glutamine was found to be the best for somatic embryogenesis (Thiruvengadam et al., 2006, Thiruvengadam et al., 2007, Thiruvengadam et al., 2013, Thiruvengadam et al., 2013).

From last few decades, tremendous advancement has been made in cucurbitaceae family through tissue culture technique. Micropropagation techniques are already standardized in various species of cucurbitaceae family. It is assessed that several millions of plants are now propagated from various explant sources each year. Despite these advancements, much focused research is needed in various areas such as somatic embryogenesis, rooting studies, genetic engineering etc. To increase the percentage of success rate in recalcitrant genotypes there is need to choose the explant source judiciously, coupled with some improvements in media composition. Improvement in regeneration ability and acclimatization in ex-vitro condition are crucial for extreme exploitation of this family. When more importance was given to these research areas the future commercial in-vitro micropropagation of cucurbitaceae family will be revolutionized.

\section{Declaration of conflicting interests:}

The authors declare that there is no conflict of interest.

\section{References}

Abdelnour, A., Ramirez, C. and Engelmann, F. (2002). Micropropagacin of Chayote (Sechium Edule Jacq. Sw.) Apartir De Brotes Vegetativos. Agronom ameso americana, 13(2): 147-151.

Abdul-Awal, S. M., Alam, J. Md., Ali, R. Md., Hassan, N. Md., Basunia, S. R., and Rehaman, S. M. M. (2005). In-vitro propagation of Pointed gourd (Trichosanthes dioica) from shoot tips. Biotech., 4(3): 221224.

Ahmad, N. and Anis, M. (2005). In-Vitro Mass Propagation of Cucumis Sativus. Turk J. Bot., 29: 237-240.

Arekar, A. R., Janhavi, A., Arekar, S. S., Barve and Paratkar, G. T. 2012. In- vitro regeneration of Momordica dioica (Roxb.). J. of Applied and Natural Sci., 4 (2): 297303.

Bezirganoglu, I., Hwang, S. Y., Shaw, J. F., and Fang, T. J. (2013). Efficient production of transgenic melon via Agrobacteriummediated transformation. Genetics and Molecular Research, 13(2): 3218-3227.

Chaturvedi, R., and Bhatnagar, S. P. (2001). HighFrequency Shoot Regeneration From Cotyledon Explants Of Watermelon Cv. Sugar Baby. In-Vitro Cell. Dev. Biol. Plant.37: 255-258.

Choudhary, S. K., Patel. A. K., Harish, Shekhawat, S., Narpat, S., Shekhawat. 2017. An improved micropropagation system, exvitro rooting and validation of genetic homogeneity in wild female Momordica dioica: an underutilized nutraceutical vegetable crop. Physiol. Mol. Biol. Plants., 23(3): 713-722.

Chovelon, V., Restier, V., Dogimont, C. and 
Aarrouf, J. (2008). Histological study of shoot organogenesis in melon (Cucumis melo L.) after genetic transformation. Cucurbitaceae 2008, Proceedings of the $I X^{\text {th }}$ EUCARPIA meeting on genetics and breeding of Cucurbitaceae (Pitrat $M$, ed), INRA, Avignon (France), May 21-24th, 2008.

Claveria, E., Garcia-mas, J. and Dolcet-Sanjuon, R. (2005). Optimization of cucumber Doubled Haploid Line production using invitro rescue of In-vivo Induced Parthenogenic embryos. J. Amer. Soc. Hort. Sci., 130(4): 555-560.

Compton, M. E., Brenda, L., Pierson and Staub, J. E. (2001). Micropropagation for recovery of Cucumis hystrix. Plant Cell, Tissue and Organ Culture, 64: 63-67.

Compton, M. E. and Gray, D. G.(1992). Micropropagation as a means of rapidly propagating Triploid and tetraploid watermelon. Proc. Fla. state Hort. soc, 105:352-354.

Dabauza, M., Bordas, M., Salvador, A., and Roig, L. A. (1997). Plant regeneration and Agrobacterium-mediated transformation of cotyledon explants of Citrullus colocynthis L. Schrad. Plant Cell Reports, 16: 888-892.

Debeaujon, I. and Branchard, M. (1993). Somatic embryogenesis in Cucurbitaceae. Plant Cell, Tissue and Organ Culture, 34: 91-100.

Debnath, B., Sinha, S. and Sinha, R. K. (2013). In-Vitro Differentiation And Regeneration of Momordica Cochinchinensis (Lour.) Spreng . Ind. J. of Plant Sci., 2(2): 23193824.

Debnath, B., Sinha, S. and Sinha, R. K. 2013. Rapid in vitro differentiation and regeneration of Momordica dioicaRoxb. Ind. J. of Plant Sci., ISSN: 2319-3824, 2 (3): 4347.

Devendra, N. K., Subhash, B. and Seetharam, Y. N. 2009. Callus growth and plant regeneration in Momordica dioica (Roxb.) Wild. Cucurbitaceae. American-Eurasian J. of Sustainable Agric., 3(4): 743-748, ISSN 1995-0748 @ 2009.

Devendra, N. K., Rajanna, L., Sheetal, C. and Seetharam, Y. N. (2008). In-vitro Clonal Propagation of Trichosanthes cucumerina L. var. cucumerina. Plant Tissue Cult. and
Biotech. 18(2): 103-111.

Devi, T., Rajasree, V., Premalakshmi, V. and Hemapra, K. (2017). In-vitro Protocol for Direct Organogenesis in Momordica cymbalaria. Fenzl. Int. J. Curr. Microbiol. App. Sci., 6(4): 2392-2402.

Elmeer, K. M. S., Thomas, F., Gallagher, and Hennerty, M. J. (2009). RAPD-based detection of genomic instability in cucumber plants derived from somatic embryogenesis. African J. of Biotech.8(14): 3219-3222.

Faria, A. L., Tanziman, A., Karim, R., Islam, R., and Hossain, M. (2013). Rapid in-vitro clonal propagation of two hybrid muskmelon cultivars and their field evaluation in agro climatic condition of Bangladesh. J. of Genetic and Envi. Resou. Conservation, 1(3):247-253.

Firoz Alam M., Ruhul, A., Ekhlas, U. M. and Sudhan. (2015). Regeneration of Shoot from Nodal explants of Cucumis sativus considering different Hormonal concentration. Inter. Research J. of Biol. Sci., 4(7): 48-52.

Ghive, D. V., Raut, N. W. And Ghorade, R.B. (2006). Tissue Culture Studies in Spine Gourd (Momordica dioicaRoxb.). Inter. J. of Plant Sci., 1(2): 266-268

Ghive, D. V., Ghorade, R. B., Khedekar, R. P., Jeughale, G. S. and Raut, N. W. 2006. In Vitro Rooting Studies in Spine Gourd (Momordica dioicaRoxb.). Asian J. of Biol. Sci., 1(2): 146-148.

Govind, R. K., Singh, M., Rai, N. P., Bhardwaj, D. R. and Kumar, S. 2012. In-Vitro propagation of spine gourd (MomordiacadioicaRoxb.) and assessment of genetic fidelity of micropropagated plants using RAPD analysis. Physiol. Mol. Biol. Plants., 18(3): 273-280.

Gray, D. J., McColley. D. W., and Michel, E. 1993. High Freequency somatic embryogenesis from quiescent seed cotyledons of Cucumis melo cultivar. J. Amer. soc. Sci., 118(3): 425-432.

Guma, T. B., Kahia, J., Justus, O., Peter, N. K. 2015. Standardization of In-Vitro Sterilization and Callus Induction Protocol for Leaf Explants of Anchote: Coccinia abyssinica. Int. J. of Research and 
Development in Pharmacy and Life Sci. 4(2); 1427-1433.

Han, J. S., Oh, D. G., Mok, I. G., Park, H. G. and Kim, C. K. (2004). Efficient plant regeneration from cotyledon explants of bottle gourd (Lagenaria siceraria Standl.). Plant Cell Rep.23:291-296.

Hasbullah, N. A., Mohammad, M., Lassim, Muhammad, A., Mazlan, Siti, Z., Lood, Muhamad, A. and Mohamed, A. 2017. Mass Propagation of Lagenariasiceraria through in-vitro Culture. J. of Advanced Agric. Technologies 4(1).

Hisajima, S. And Yujl, A. 1989. Micropropagation of Cucumber Plant through Reproductive Organ Culture and Semi-aquaculture of Regenerated Plants. Japan. J. Trop. Agr. 33(1): 1-5.

Haque, M. E., Sarkar, M. A. R., Mahmud, M. A., Rezwana, D., and Sikdar, B. (2008). In-Vitro Propagation Of Pumpkin and Ash gourd through nodal segments. J. bio-sci, 16: 6771.

Hoque, M., Hossain, S., Alam, S., Arima and Islam, R. 2007. Adventitious Shoot Regeneration from Immature Embryo Explant Obtained from Female $\times$ Female Momordica dioica. Plant Tissue Cult. and Biotech., 17(1): 29-36.

Hoque, A.,Islam, R.,Arima, S. 2000. High frequency plantlet regeneration from cotyledon-derived callus of Momordica dioica (Roxb.) Wild. Phytomorphology, 50 (3/4): 267-272 ref.19.

Huda, A. K. M. N. and Sikdar, B. (2006). In-vitro Plant Production through Apical Meristem Culture of Bitter Gourd (Momordica charantia L.). Plant Tissue Cult. and Biotech. 16(1): 31-36.

Ikram-ul Haq, Arshad, Z. and Taseer. (2013). Establishment of Plant Regeneration Protocol in Cucumber: Fruit Juices Used as Carbon Source. Inter. J. of Sci. and Research, 6(4), 81-84.

Jadhav, S., Parmar, L. D. and Chauhan, R. M., 2015. Response of spine gourd genotypes (Momordica dioica Roxb.) to micropropagation. $\quad 4^{\text {th }} \quad$ International Conference on Agriculture and Horticulture, 4:2 http://dx.doi.org/10.4172/21689881.S1.016.
Jamatia, D. 2016. Assessment of Variability and Standardization of Protocol for Micropropagation in Spine gourd (Momordica dioicaRoxb.). A thesis submitted to Maharana Pratap University of Agricultural andTechnology.

Jasmine, R. and Mian, M. A. K. (2016). Callus induction and efficient plant regeneration in Cucumber (Cucumis sativus L.). J. Biosci. Agric. Res. 09(02): 796-803 .

Kapadia, C., Patel, N., Patel, N., Ahmad, T. 2018. Optimization of Culture Medium for Higher Multiplication and Efficient Micropropagation of Spine Gourd (Momordica dioica Roxb.). J. of Experimental Biol. and Agric. Sci., 6(3): 599- 605 .

Karim, M. A. And Ullah, M. A. (2011). In-Vitro Regeneration of Teasle Gourd. 2011 2nd International Conference on Biotechnology and Food Science IPCBEE vol.7 (2011) (C) (2011) IACSIT Press, Singapore

Karim, M. A. and Ullah, M. A. 2011. In-vitro regeneration of teasle gourd. Paper presented in $2^{\text {nd }}$ Int. Conference on Biotech. And Food Sci., IPCBEE.7:144-148.

Karim, M. A. 2013. High Frequency Shoots Regeneration from Cotyledon Explants of Teasle Gourd via Organogenesis. Journal of Life Scie. and Technologies, 1(1): doi: 10.12720/jolst.1.1.79-83.

Karim, M. A. and Ahmed, S. U. 2010. Somatic Embryogenesis and Micropropagation in Teasle Gourd. International J. of Environmental Sci. and Development, 1(1): 10-14. ISSN: 2010-0264.

Kausar, M., Parvin, S., Haque, M. E., Khalekuzzaman, M., Sikdar, B. and Islam, M. A. (2013). Efficient Direct Organogenesis From Shoot Tips and Nodal Segments of Ash Gourd (Benincasa Hispida L.). J. life Earth Scie., 8: 17-20.

Kawale, M. V. and Choudhary, A. D. (2009). InVitro Multiple Shoot Induction In Trichosanthes cucumerina L. Ind. J. Plant Physiol., 14(2): 116-123.

Keng, C. L. and Hoong, L. K. (2005). In-vitro Plantlet Regeneration From Nodal Segment of Musk melon (Cucurbita pepo L.). Biotechnology. 4(4): 354-357.

Khalekuzzaman, M., Khatun, M. M. Rashid, M. 
H. Sheikh, M. I., Sharmin, S. A. and Alam, I. (2012). Micropropagation of an Elite F1 Watermelon (Citrullus lanatus) Hybrid from the Shoot Tip of Field Grown Plants. Brazilian Archives of Biol. And Tech., 55(3): 335-340.

Khatun, M. M., Hossain, M. S., Khalekuzzaman, M., Rownaq, A. And Rahman, M. 2010. In-Vitro Plant Regeneration from Cotyledon and Internodes Derived Callus in Watermelon (Citrullus lanatus Thumb.). Int. J. Sustain. Crop Prod. 5(4):25-29.

Khatun, M. M., Hossain, M. S., Haque, M. A. and Khalekuzzaman, M. (2010). In- vitro propagation of Citrullus lanatus Thumb. from nodal explants culture. J. Bangladesh Agril. Univ,8(2): 203-206.

Kielkowska, A. and Michael, J., Havey. (2011). In-vitro flowering and production of viable pollen of cucumber. Plant Cell Tiss. Organ. Cult., doi:DOI 10.1007/s11240-011-0075-8 al, C.-M. e. (n.d.).

Kim, K., Chang Kil Kim, and Jeung-Sul Han. (2010). In-vitro regeneration from cotyledon explants in fig leaf gourd (Cucurbita ficifolia Bouche.) a rootstock for Cucurbitaceae. Plant Biotechnol. Rep., 4:101-107.

Komal, R. (2011). Effect of BAP and IAA on callus formation and plant regeneration in pointed gourd. Research Article, Biotechnol. Bioinf. Bioeng, 1(1):59-62.

Komal, R. (2011). In-vitro Plant Regenera of Trichosanthes dioica. Ind. J. Agric. Res., 45(2): 140-145.

Komal, R. (2011). One step method of plantlet regeneration in Trichosanthes dioica Roxb. An approach towards cost effective and shorter protocol . African J. of Biotech. 10(1): 9-12.

Krug, M. G. Z., Stipp, L. C. L., Rodriguez, A. P. M. and Mendes, B. M. J. (2005). In-vitro organogenesis in watermelon cotyledons. Pesq. Agropec. Bras., Brasília, 40(9): 861865.

Kulkarni, G. R. 1999. Micropropagation studies in Kartoli (Momordica dioicaRoxb.). A thesis submitted to Mahatma Phule Krishi Vidyapeeth, Rahuri-413 722.

Li, J., Li, X. M., Qin, Y. G., Tang, Y., Wang, Ma, C. and Li, H. X. (2011). Optimized system for plant regeneration of watermelon
(Citrullus lanatus Thumb.). African J. of Biotech. 10(48:9760-9765.

Mahazabin, F., Parvez, S., and Alam, M. F. (2008). Micropropagation Of Cucurbita Maxima Duch. Through Shoot Tip Culture . J. bio-scie.16: 59-65.

Malex, M. A., Khanam, D., Khatun, M., Molla, M. H. and Mannan, M. A. (2010). In- Vitro Culture Of Pointed Gourd (Trichosanthes dioica Roxb.). Bangladesh J. Agril. Res., 35(1): 135-142.

Margaret, S., Maheswari, U., Ambethkar, Vasudevan, Sivanandhan and Selvaraj. (2014). Direct regeneration of multiple shoots from nodal explants of West Indian Gherkin (Cucumis anguria L.). Inter. J. of Innovative Research in Sci, Engineering and Technology, (6): 13876-13881.

Mohammadi, J. and Sivritepe, N. 2007. In-vitro Clonal Propagation of Cucumis sativus L. by Shoot tip culture. J. Biol. Scie, 7(4): 653657.

Moideen, R. S., Prabha, L. A. 2013. In-Vitro Plant Regeneration of Luffa acutangulaRoxb. Var Amara Lin.: An Important Medicinal Plant. Int. J. of Sci. and Research (IJSR), 23197064.

Moideen, R. S. And Prabha, L. A. 2014. In-vitro Studies on Luffa acutangula Lin. Var. Amara. Roxb - An Important Medicinal Plant. Int. J. Pharm Bio. Sci. 5(1): 925 933.

Mustafa, Md., Swamy, T. N., Raju, S. and Peer, S. N. 2013. Multiple shoot inductionfrom the nodal cultures of teasle gourd (Momordica dioicaRoxb.). Int. J. of Biosciences, doi: http://dx.doi.org/10.12692/ijb/3.2.8-12. 3(2): 8-12.

Mustafa, Md., Swamy, T. N., Raju, S., Mohammad, S. K. and Suresh, V. 2012. Regeneration of Plantlets from Nodal Cultures of Momordica DioicaRoxb. Int. J. Pharm Bio. Sci. 3(4): 92 - 96.

Nabi, S. A., Rashid, M. M., Al-Amin, M. and Rasul, M. G. 2002 . Organogenesis in Teasle Gourd (Momordiacadioica Roxb.). Plant Tissue. Cult., 12(2): 173 - 183.

Nabi, S. A., Rasul, M. G., Al-Amin, M., Rasheed, M. M., Ozaki, Y. and Okubo, H. 2002 ${ }^{\mathrm{b}}$. Invitro multiplication of kakrol (Momordica dioica Roxb.). J. of the Faculty of Agric., 46 
(2): 303-309.

Nanasato, Y., Konagaya, K., Okuzaki, A., Tsuda, M. and Tabei, Y. (2013). Improvement of Agrobacterium-mediated transformation of cucumber (Cucumis sativus L.) by combination of vacuum infiltration and cocultivation on filter paper wicks. Plant Biotechnol Rep, 7:267-276.

Pal, S. P., Alam, I., Anisuzzaman, M., Sarker, K. K., Sharmin, S. A. and Alam, M. F., (2007). Indirect Organogenesis in Summer Squash (Cucurbita Pepo). Turk J. Agric., 31: 63-70.

Parvin, S., Kausar, M., Haque, E., Khalekuzzaman, Sikdar, B. and Islam, M. A. (2013). In-vitro propagation of muskmelon (Cucumis melo L.) from nodal segments, shoot tips and cotyledonary nodes. Rajshahi University J. of life and earth and Agric. scie., 41: 71-77.

Patel, M. G. and Kalpesh, B. I. 2015. Momordica dioica Roxb. (Spine Gourd): Multiple shoot induction from nodal cultures and its antidiabetic activity. J. of Medicinal Plants Studies,3(6): 82-88

Rahman, H., Shahinozzaman, M., Karim, M. R., Hoque, A., Hossain, M. M. and Rafiul, A. K. M. (2012). Rapid in-vitro clonal propagation of a hybrid muskmelon ( Cucumis melo L.) cultivar from seedling explants. Int. J. Agr. and Agri. R., 2(1): 4752.

Rajasekharan, P. E., Bhaskaran, Sunitha, John, K., Joseph, Koshy, Eapen, P., Antony, V. T. 2012. In-Vitro Multiplication and Conservation of Wild Momordica sahyadrica. IUP J. of Biotech., 7: 50-56.

Raju, S., Chithkari, R., Bylla, P. and Mustafa, Md. 2015. Molecular Confirmation of Sex in Regenerated Plantlets of Spine gourd (Momordica dioicaRoxb. Ex. WILD) by using RAPD analysis. $J$. of Experimental Biol. and Agric.Sci., 3(5): 407-414.

Rama krishna, D, and Shasthri, T. (2015). Adventitious Rooting and Proliferation from Different Explants of Citrullus colocynthis L. Schrad an Endangered Medicinally Important Cucurbit. Asian J. of Biotech., 7(2): 88-95.

Randall, P., Niedz, L., Smith, S. S., Kerry, B., Dunbar, Christine, T. Haeey. H. (1989). Factors influencing shoot regeneration from cotyledonary explants of Cucumis melo. Plant Cell, Tissue and Organ Culture, 18: 313-319.

Saima malik, Zia, M., Riaz-ur-Rehaman, and Choudhary, M. F. (2007). In-vitro plant regeneration from direct and indirect organogenesis of Momordica charantia. Pakistan J. of Biol. Sci., 10(22), 4118-4122.

Sangeetha, P. and Venkatachalau, P. (2011). Induction of multiple shoots from shoot tip explants of cucumber (Cucumis sativus 1.). Plant Cell Biotechnology and Molecular Biol., 12(1-4):

Sarowar, S., Oh, H. Y., Hyung, N. I., Min, B. W., Harn, C. H., Yang, S. K., Ok, S. H. Shin, and J.S. 2003. In-vitro micropropagation of a Cucurbita interspecific hybrid cultivar - a root stock plant. Plant Cell, Tissue and Organ Culture, 75: 179-182.

Satapathy, G. and Thirunavoukkarasu, M. 2014. Cytokinins effect on direct shoot bud regeneration from leaf segments of bitter cucumber (Cucumis trigonus Roxb.). Int. J. Pure App. Biosci., 2(1): 139-146.

Savitha, R., Shasthree, T., Sudhakar, Mallaiah, B. 2010. High Frequency of Plantlet Regeneration and Multiple Shoot Induction from Leaf and Stem Explant of Citrullus colosynthis (1.) schrad, an endangered medicinal cucurbit. Int. J. of Pharma and Bio Sci., 1(2).

Selvaraj, N., Vasudevan, A., Manickavasagam, M. and Ganapathi. A. 2006. In-Vitro Organogenesis and Plant Formation in Cucumber. Biologia Plantarum, 50 (1): 123126.

Shasthree, T., Ramakrishna, D., Imran, M. A. and Chandrashekar, Ch. (2014). Adventitious Shoot Organogenesis and Plant Regeneration from Leaf and Cotyledon Explants of Citrullus colocynthis. J. of Herbs, Spices and Medicinal Plants, 20:235-244.

Shekhawat, M. S., Shekhawat, N. S., Harish, Kheta, R., Phulwaria, M. and Gupta, A. K. 2011. High frequency Plantlet Regeneration from nodal segment culture of Female Momordiacadioica (Roxb.). J. crop Sci. Biotech., 14(2): 133-137.

Singh, N., Raj, A., Sharma, A. and Kuma, P. (2011). Efficient in-vitro regeneration 
system using cotyledon explants in Indian cultivar of sponge gourd (Luffa Cylindrica Roem.) compatible to Agrobacterium tumifaciens mediated transformation. Reviewed Proceedings of National Seminar on Internet: Applications in Research, 3640, ISBN: 978-81-920945-1-9.

Saurabh, S., Prasada, D., Ambarish, S. and Vidyarthi (2017). In-vitro Propagation of Trichosanthes dioica Roxb. for Nutritional Security. J. Crop Sci. Biotech., 20(2): 81-87.

Srivastava, A. and Roy, S. (2012). Callus Multiplication of a Medicinally Important Vegetable Luffa cylindrica. Int. J. Pharm. Bio. Sci.,3(3): 526-531

Sultana, R. S., and Miha, B. M. A. (2003). In-vitro Propagation of Karalla ( Momordica charantia Linn.) from Nodal Segment and Shoot Tip. J. Biol. Scie. 3(2): 1134-1139.

Sultana. R. S., Miha, B. M. A., Rahaman, M. M. and Mollah, M. U. (2005). Asceptic Multiplication and Maintanance of Bitter gourd (Momordica charantia) as affected by sucrose, Agar and pH. J. Biol. Scie., 5(6): 781-785.

Suratman, F., Huyop, F. and Parveez, G. k. A. (2009). In-vitro shoot regeneration of Citrullus vulgarisSchrad (Watermelon). Biotechnology, 8(4): 393-404.

Swamy, T. N., Bylla, P., Suresh, V. and Mustafa, Md. 2015. In-vitro regeneration of Momordica dioicaRoxb. Through leaf derived callus. Sci. Res. Reporter., 5(2): 177- 180.

Thakur, G. S., Sharma, R., Sanodiya, Pandey, M., Baghel, R., Gupta, A., Bisen, P. S. (2011). High frequency in-vitro shoot regeneration of Momordica balsamina, an important medicinal and nutritional plant. African J. of Biotech, 10(70): 15808-15812.

Thiruvengadam, M., Mohamed, S. V., Yanf, C. H. and Jayabalan, N. (2006). development of embryogenoic susupension culture of bitter melon ( Momordica dioica L.). Scietia Horticultureae, 109: 123-129.

Thiruvengadam, M., Rekha, S. K., Yang, C. H. (2007). Somatic embryogenesis and plant regeneration from petiole derived callus of spine gourd (MomordicadioicaRoxb. Ex Wild). Functional plant sci. and Bio technology, 1(1): 200-206.
Thiruvengadam, M., Chung M-III, and Se-chun Chun. (2012). Influence of polyamines on in-vitro organogenesis in bitter melon (Momordica charantia L.) . J. of Medicinal Plants Research, 6(19: 3579-3585.

Thiruvengadam, M., Jeyakumar, J. J., Kamaraj, M., Lee, Y. J. and Chung, I. M. (2013). Plant regeneration through somatic embryogenesis from suspension cultures of Gherkin (Cucumis anguria L.). Austrelian J. of crop scie.,7(7): 969-977.

Thiruvengadam, M., Rekha, K. T., Jayabalan, N., Praveen, N., Kim, E. H. and Chung, I. M. 2013. Effect of exogenous polyamines enhances somatic embryogenesis via suspension cultures of spine gourd (MomordicadioicaRoxb. Ex. WILD). Australian J. of CropSci., 7(3): 449-453.

Thiruvengadam, M., Nagella, P., Ill-Min Chung. 2012. Plant regeneration from alginateencapsulated shoot tips of Momordica dioica for short term storage and germplasm exchange and distribution. Plant Omics J. 5(3): 266-270.

Thomas, T. D. and Sreejesh, K. R. (2004). Callus induction and plant regeneration from cotyledonary explants of ash gourd (Benincasa hispida L.). Scientia Horticulturae, 100: 359-367.

Umamaheswari, C., Ambethkar, A., Margaret, F. S. and Selvaraj, N. (2014). In-Vitro Multiple Shoot Regeneration From Cotyledon Explants Of Luffa acutangula (L.) Roxb. Inter. J. of Current Biotech. 2(7):7-13.

Usman, Hussain, Z. and Fatima, B. (2011). Somatic Embryogenesis And Shoot Regeneration Induced in Cucumber Leaves . Pak. J. Bot., 43(2): 1283-1293.

Valdez-Melara, M., García, A., Delgado, M., Andres, M., Gatica-Arias. and RamírezFonseca, P. 2009. In-vitro plant regeneration system for tropical butternut squash genotypes (Cucurbita moschata). Rev. Biol. Trop. (Int. J. Trop. Biol. ISSN-0034-7744), 57(Suppl. 1): 119-127.

Vedat, P., Onay, A., Yildirim, H., Adiyaman, F., Ifiikalan, C. and Bafiaran, D. 2002. Adventitious Shoot Organogenesis and Plant Regeneration from Cotyledons of Diploid Diyarbakr Watermelon (Citrullus lanatus cv. Surme). Turk J. Biol. 27(2003): 101-105. 
Velivela, Y., Narra, M., Ellendula, R., Kota, S., Abbagani, S. 2016. Establishment of in-vitro regeneration from petiole explants and assessment of clonal fidelity by ISSR markers in Luffa acutangula L. Roxb. J. of Applied Biol. and Biotech. 4(03): 041-045.

Venkateshwaralu, M. 2010. Cytokinin induced multiple shoot induction from node explants of Cucumis melo var. utilissimus - A potentially important medicinal plant. Int. J. of Plant Protection, 3(1): 107-110.

Venkateshawaralu, M. (2012). Direct multiple shoots proliferation of Muskmelon (Cucumis melo L.) from shoot tip explants. Int. J. of Pharma and Bio Sci., 3.

Verma, A. K., Kumar, M., Tarafdar, S., Singh, R., and Takur, S. (2014). Development of
Protocol for Micropropagation of Gynoecious Bitter Gourd (Momordica Charantia L). Inter. J. of Plant, Animal and Environmental Sci., 4: 275-280.

Yutaka, T., Tomohiro, Y., Toshikazu, M., and Takeshi, O. (1998). Plant Regeneration via Shoot Organogenesis from Cotyledons in Two Wild Cucumis Species, C. Figarei and C. metuliferus. JARQ, 32: 281-286.

Zohura, F.T., Haque, M. E., Islam, M. A., Khalekuzzaman, M., Sikdar, B. (2013). Establishment of an efficient In-Vitro regeneration system of Ridge Gourd (Luffa acutangula L. Roxb) from immature embryo and cotyledon explants. Int. J. of Scientific and Technology Research, 2(9).

\section{How to cite this article:}

Sangram S. Dhumal, B. Veerendra Naik and Mansinghraj S. Nimbalkar. 2020. Advances in Tissue Culture of Cucurbits: A Review. Int.J.Curr.Microbiol.App.Sci. 9(08): 2887-2910. doi: https://doi.org/10.20546/ijcmas.2020.908.324 